Article

\title{
Pricing Energy and Ancillary Services in a Day-Ahead Market for a Price-Taker Hydro Generating Company Using a Risk-Constrained Approach
}

\author{
Perica Ilak *, Slavko Krajcar, Ivan Rajšl and Marko Delimar \\ Faculty of Electrical Engineering and Computing, University of Zagreb, Unska 3, Zagreb HR-10000, \\ Croatia; E-Mails: slavko.krajcar@fer.hr (S.K.); ivan.rajsl@fer.hr (I.R.); marko.delimar@fer.hr (M.D.) \\ * Author to whom correspondence should be addressed; E-Mail: perica.ilak@fer.hr; \\ Tel.: +385-1-6129-693; Fax: +385-1-6129-890.
}

Received: 13 October 2013; in revised form: 24 March 2014 / Accepted: 8 April 2014 /

Published: 11 April 2014

\begin{abstract}
This paper analyzes a price-taker hydro generating company which participates simultaneously in day-ahead energy and ancillary services markets. An approach for deriving marginal cost curves for energy and ancillary services is proposed, taking into consideration price uncertainty and opportunity cost of water, which can later be used to determine hourly bid curves. The proposed approach combines an hourly conditional value-at-risk, probability of occurrence of automatic generation control states and an opportunity cost of water to determine energy and ancillary services marginal cost curves. The proposed approach is in a linear constraint form and is easy to implement in optimization problems. A stochastic model of the hydro-economic river basin is presented, based on the actual Vinodol hydropower system in Croatia, with a complex three-dimensional relationship between the power produced, the discharged water, and the head of associated reservoir.
\end{abstract}

Keywords: hydropower plant; opportunity cost; water shadow price; day-ahead market; risk-aversion; conditional value at risk; ancillary services

\section{Introduction}

This paper formulates a hydro-economic river basin model (HERBM) of a price-taking hydro generating company (GENCO, Zagreb, Croatia) which participates in a simultaneous energy and ancillary services day-ahead markets (DAMs) [1-5]. In order to successfully bid on a market, a hydro 
GENCO first needs to determine energy and ancillary services marginal cost curves. Since the direct cost of energy generation for a hydro GENCO is virtually zero compared to a fossil fuel GENCOs, consequently creating a marginal cost curve is more complicated compared with finding a generation cost curve first derivative for a fossil fuel GENCO. This paper will tackle this problem, and propose easy to implement linear formulation in a form of a constraint. In this paper an opportunity cost of water is viewed as a marginal cost of water. The idea behind the opportunity cost of water is that generating one $\mathrm{MWh}$ in a given hour means not being able to generate one MWh in some future hour. Therefore, for a hydro GENCO, the foregone earnings from future generation constitute the opportunity cost of current energy generation. A similar study is done in [6] where a fixed head of a hydro power plant (HPP) is considered. In one of the fundamental works, a marginal cost of water is assumed to be constant over the planning horizon [7,8]. For a more realistic approach, a water shadow price should change over the planning horizon every time the reservoir capacity constraints are reached $[9,10]$. This was the case in this research. A lot of work has been done in a field of bidding curve optimization models and a review of these models can be found in [11], with some early works in [12-14].

Modeling of ancillary services is specifically addressed in this research using simple linear formulation where automatic generation control (AGC) state (ramp up, ramp down, no ramp) is considered as a random variable. Detailed ancillary services models are important in order to encourage competitiveness and introduction of new ancillary services providers which consequently results in higher penetration of renewable energy sources (RES) particularly wind [15-17].

In a short-term planning most of the parameters are usually considered as known and the resulting models are deterministic $[18,19]$. In this paper a stochastic short-term planning model is presented, which enables implementation of a risk measure. It is particularly convenient to use a conditional-value-at-risk (CVaR), a relatively new risk measure introduced in [20]. CVaR is a coherent measure of risk $[21,22]$ which is important for the successful representation of real life occurring risks and for implementation in convex optimization problems [23]. This paper analyzes the price-taker hydro GENCO which participates simultaneously in energy and ancillary services DAMs. This paper contributes to the previous works [7-10] with the approach which combines innovative usage of the hourly $\mathrm{CVaR}$, the probability of occurrence of AGC states and the opportunity cost of water to determine the energy and ancillary services marginal cost curves and consequently to determine a bid prices for energy and ancillary services. The proposed approach is in a linear constraint form and is easy to implement in optimization problems.

Relationships between the head of the associated reservoir(s), the discharged water and the generated power is considered. Models describing these relationships are available in [24-29]. Therefore, in Section 2, the cascade hydropower system (HPS) is carefully modeled as HERBM using the mixed-integer linear programming (MILP) formulation. Afterword's the ancillary services model is formulated and the risk-constrained approach for pricing energy and ancillary services is introduced. Section 3 presents and analyzes the results on the case of HPS Vinodol (Croatia) and in Section 4 conclusions are given. 


\section{Problem Description and Formulation}

In this chapter, hourly water marginal costs are determined. The profit maximization objective function is formulated. Hourly $\mathrm{CVaR}$ as a risk measure is formulated. Ancillary services model is formulated with AGC state as a discrete random variable. Probability of occurrence of AGC states are later used as a rule for redistributing the water marginal cost along the energy, the regulation and the 10 min spinning reserve. Afterwards the energy, regulation and 10 min spinning reserve marginal costs are used for determining an hourly bidding curves.

\subsection{Hydro Constraints}

The continuity equation of the hydro reservoirs is formulated as Equations (1) and (2). The variable defined after semicolon denotes the associated dual variable:

$$
\begin{gathered}
X(i, t, \omega)=X(i, t-1, \omega)+M \cdot\left[W(i, t, \omega)+\sum_{j \in U}\left\{q\left(j, t-\tau_{i j}, \omega\right)+s\left(j, t-\tau_{i j}, \omega\right)\right\}\right. \\
-(q(i, t, \omega)+s(i, t, \omega))] \forall i \in I, \forall t \in T, \forall \omega \in \Omega \\
X(i, t, \omega) \leq X_{\max }(i) ; \kappa^{X_{\max }}(i, t, \omega) \\
X(i, t, \omega) \geq X_{\min }(i) ; v^{X_{\min }}(i, t, \omega) \\
s(i, t, \omega) \geq B_{\min } ; \forall i \in I, \forall t \in T, \omega \in \Omega
\end{gathered}
$$

For unit consistency, it should be noted the time periods of $1 \mathrm{~h}$ are considered. The $\tau_{i j}$ is the time delay for water transportation between reservoirs $i$ and $j$.

\subsection{Head Dependent Power Output}

The performance curves (Figure 1) are modeled through a piecewise linear formulation of a Hill chart [30]. Non-concavities are modeled through the use of binary variables. Figure 1a shows three-piece linear performance curves.

Figure 1. (a) The three-dimensional unit performance curves; (b) The operating range of HPP when committed in energy and ancillary service markets.

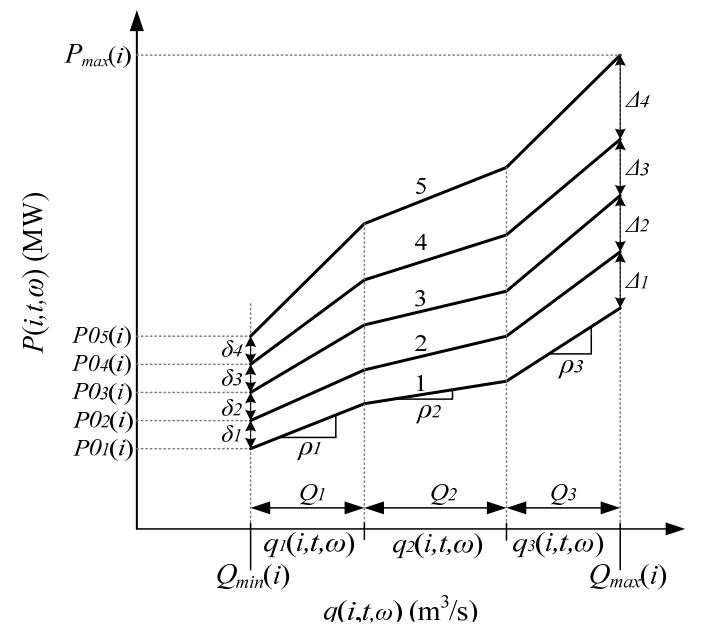

(a)

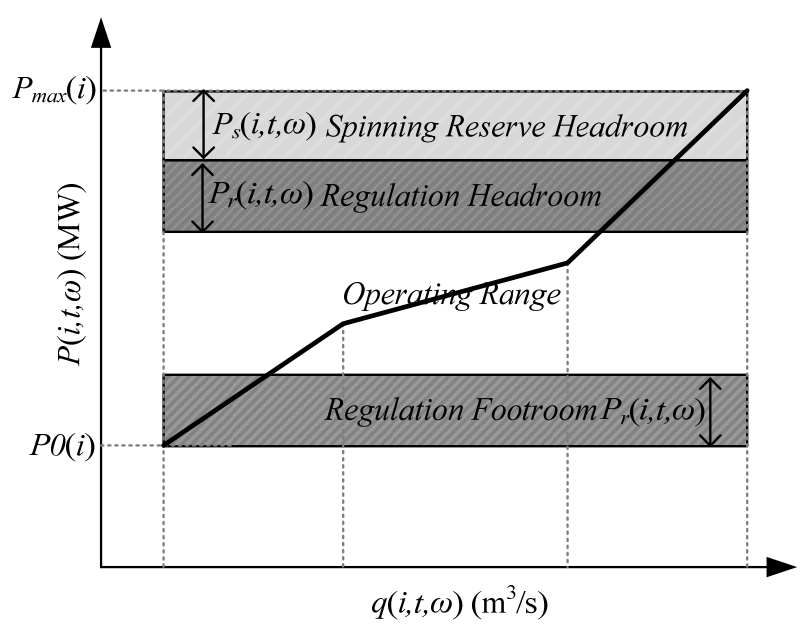

(b) 
The slope $\rho$ is defined by HPP conversion capabilities $\left(\mathrm{MWs} / \mathrm{m}^{3}\right)$. The five performance curves are associated for the five water contents intervals. Activation of the corresponding performance curve is done by the approach presented in [31]. Unlike [32,33] the operation of HPP is not restricted to the local best efficiency points. Activation of the performance curves is modeled with Equations (3)-(6).

The performance curves are activated according to the four binary variables $d_{1}, d_{2}, d_{3}$ and $d_{4}$ in Equations (3)-(6) using the average value of stored water in certain time step $t$ Equation (3) instead of using the final reservoir water content of the time step $t[26]$ :

$$
\begin{gathered}
X_{\mathrm{avg}}(i, t, \omega)=\frac{X(i, t, \omega)+X(i, t-1, \omega)}{2} \quad \forall i \in I, \forall t \in T, \forall \omega \in \Omega \\
X_{\mathrm{avg}}(i, t, \omega) \geq X_{1}(i) \cdot\left[d_{1}(i, t, \omega)-d_{2}(i, t, \omega)\right]+X_{2}(i) \cdot\left[d_{2}(i, t, \omega)-d_{3}(i, t, \omega)\right] \\
+X_{3}(i) \cdot\left[d_{3}(i, t, \omega)-d_{4}(i, t, \omega)\right]+X_{4}(i) \cdot d_{4}(i, t, \omega), \forall i \in I, \forall t \in T, \forall \omega \in \Omega \\
X_{\mathrm{avg}} \leq X_{\max }(i) \cdot d_{4}(i, t, \omega)+X_{1}(i) \cdot\left[1-d_{1}(i, t, \omega)\right]+X_{2}(i) \cdot\left[d_{1}(i, t, \omega)-d_{2}(i, t, \omega)\right] \\
+X_{3}(i) \cdot\left[d_{2}(i, t, \omega)-d_{3}(i, t, \omega)\right]+X_{4}(i) \cdot\left[d_{3}(i, t, \omega)-d_{4}(i, t, \omega)\right], \forall i \in I, \forall t \in T, \forall \omega \in \Omega \\
d_{1}(i, t, \omega) \geq d_{2}(i, t, \omega) \\
d_{2}(i, t, \omega) \geq d_{3}(i, t, \omega) \\
d_{3}(i, t, \omega) \geq d_{4}(i, t, \omega), \forall i \in I, \forall t \in T, \forall \omega \in \Omega
\end{gathered}
$$

Depending on the binary variables $d_{1}, d_{2}, d_{3}$ and $d_{4}$ combination the corresponding performance curve will activate. For instance if the binary variables are set to $1,0,0,0$ the performance curve Equation (8) is activated, if the binary variables are 1, 1, 1, 0 then the curve Equation (10) is activated and, etc. Formulation of the performance curves is shown in Equations (7)-(13).

$$
\begin{gathered}
P(i, t, \omega)-P 0_{1}(i) \cdot w(i, t, 0, \omega)-\sum_{b=1}^{3} q_{u}(i, t, b, \omega) \cdot \rho(i, b) \\
-P_{\max }(i) \cdot\left[d_{1}(i, t, \omega)+d_{2}(i, t, \omega)+d_{3}(i, t, \omega)+d_{4}(i, t, \omega)\right] \leq 0 \\
P(i, t, \omega)-P 0_{1}(i) \cdot w(i, t, 0, \omega)-\sum_{b=1}^{3} q_{u}(i, t, b, \omega) \cdot \rho(i, b) \\
+P_{\max }(i) \cdot\left[d_{1}(i, t, \omega)+d_{2}(i, t, \omega)+d_{3}(i, t, \omega)+d_{4}(i, t, \omega)\right] \geq 0, \forall i \in I, \forall t \in T, \forall \omega \in \Omega \\
P(i, t, \omega)-P 0_{2}(i) \cdot w(i, t, 0, \omega)-\sum_{b=1}^{3} q_{u}(i, t, b, \omega) \cdot \rho(i, b) \\
-P_{\max }(i) \cdot\left[1-d_{1}(i, t, \omega)+d_{2}(i, t, \omega)+d_{3}(i, t, \omega)+d_{4}(i, t, \omega)\right] \leq 0 \\
P(i, t, \omega)-P 0_{2}(i) \cdot w(i, t, 0, \omega)-\sum_{b=1}^{3} q_{u}(i, t, b, \omega) \cdot \rho(i, b) \\
+P_{\max }(i) \cdot\left[1-d_{1}(i, t, \omega)+d_{2}(i, t, \omega)+d_{3}(i, t, \omega)+d_{4}(i, t, \omega)\right] \geq 0, \forall i \in I, \forall t \in T, \forall \omega \in \Omega \\
P(i, t, \omega)-P 0_{3}(i) \cdot w(i, t, 0, \omega)-\sum_{b=1}^{3} q_{u}(i, t, b, \omega) \cdot \rho(i, b) \\
-P_{\max }(i) \cdot\left[2-d_{1}(i, t, \omega)-d_{2}(i, t, \omega)+d_{3}(i, t, \omega)+d_{4}(i, t, \omega)\right] \leq 0 \\
P(i, t, \omega)-P 0_{3}(i) \cdot w(i, t, 0, \omega)-\sum_{b=1}^{3} q_{u}(i, t, b, \omega) \cdot \rho(i, b) \\
+P_{\max }(i) \cdot\left[2-d_{1}(i, t, \omega)-d_{2}(i, t, \omega)+d_{3}(i, t, \omega)+d_{4}(i, t, \omega)\right] \geq 0, \\
\forall i \in I, \forall t \in T, \forall \omega \in \Omega
\end{gathered}
$$




$$
\begin{gathered}
P(i, t, \omega)-P 0_{4}(i) \cdot w(i, t, 0, \omega)-\sum_{b=1}^{3} q_{u}(i, t, b, \omega) \cdot \rho(i, b) \\
-P_{\max }(i) \cdot\left[3-d_{1}(i, t, \omega)-d_{2}(i, t, \omega)-d_{3}(i, t, \omega)+d_{4}(i, t, \omega)\right] \leq 0 \\
P(i, t, \omega)-P 0_{4}(i) \cdot w(i, t, 0, \omega)-\sum_{b=1}^{3} q_{u}(i, t, b, \omega) \cdot \rho(i, b) \\
+P_{\max }(i) \cdot\left[3-d_{1}(i, t, \omega)-d_{2}(i, t, \omega)-d_{3}(i, t, \omega)+d_{4}(i, t, \omega)\right] \geq 0 \\
\forall i \in I, \forall t \in T, \forall \omega \in \Omega \\
P(i, t, \omega)-P 0_{5}(i) \cdot w(i, t, 0, \omega)-\sum_{b=1}^{3} q_{u}(i, t, b, \omega) \cdot \rho(i, b) \\
-P_{\max }(i) \cdot\left[4-d_{1}(i, t, \omega)-d_{2}(i, t, \omega)-d_{3}(i, t, \omega)-d_{4}(i, t, \omega)\right] \leq 0 \\
P(i, t, \omega)-P 0_{5}(i) \cdot w(i, t, 0, \omega)-\sum_{b=1}^{3} q_{u}(i, t, b, \omega) \cdot \rho(i, b) \\
+P_{\max }(i) \cdot\left[4-d_{1}(i, t, \omega)-d_{2}(i, t, \omega)-d_{3}(i, t, \omega)-d_{4}(i, t, \omega)\right] \geq 0 \\
\forall i \in I, \forall t \in T, \forall \omega \in \Omega \\
q(i, t, b, \omega) \leq Q \max (i, b) \cdot w(i, t, b-1 \omega) \\
q(i, t, b, \omega) \geq Q_{\max }(i, b) \cdot w(i, t, b, \omega), \quad \forall b \in B, \forall i \in I, \forall t \in T, \forall \omega \in \Omega \\
\sum_{b=1}^{3} q(i, t, b, \omega)+Q_{\min }(i) \cdot w(i, t, 0, \omega)
\end{gathered}
$$

\subsection{Day-Ahead Market}

In this work the hydro GENCO participates in the simultaneous energy and ancillary service DAM. Markets are considered competitive enough to assume the analyzed GENCO is a price-taker. The 10 min spinning reserve and regulation markets are considered as the ancillary service markets. In DAM considered here the independent system operator (ISO) will commit GENCOs in a similar way as ISO did in the vertically integrated structure using security constrained unit commitment (SCUC). Suppliers submit their bids to supply the forecasted daily inelastic demand and ISO uses the bid-in costs submitted by GENCOs for each generating unit (multi-part bids that reflect start-up costs, minimum generation costs, capacity offered, running costs, etc.) to minimize cost of operation and determine which units will be dispatched in how many hours and calculate the corresponding market clearing prices (MCPs) while the system security is retained The prices of energy and ancillary services are set at the shadow price of the market clearing constraints for the corresponding product and as a result, generating units are dispatched to maximize their profits given the prices of energy and ancillary services. Such market design is incentive for a competitive generator to select as a weakly dominating strategy bidding the actual generation cost and operation parameters. DAM market modeled here is assumed to be similar to New York DAM (New York Independent System Operator-NYISO) [34]. 


\subsection{Ancillary Services}

Besides participating in energy DAM, GENCO participates in the $10 \mathrm{~min}$ spinning reserve DAM and the regulation DAM. Ancillary services markets are country-dependent and a review of these markets designs is available in [35]. An HPP parameter important for modeling frequency regulation services is the maximum sustain ramp rate parameter (MSR [MW/min]) which defines how much unit can increase (MSR up) or decrease (MSR down) its output in time period of minute. The regulation and spinning reserve services are modeled based on the approach presented in [36], with the improvements Equations (16)-(21) regarding probability of occurrence of particular AGC state. When GENCO participates in the regulation DAM, the following AGC states may occur:

- Regulation-up: HPP power output increases. GENCO earns on available regulation capacity $P_{r}(t, \omega)$ priced at $\pi_{r}(t, \omega)$ and on electricity produced for regulation service $E_{r}(t, \omega)$ priced at $\pi_{\text {spot }}(t, \omega)$ in a time period $t$ and a price scenario $\omega$. Probability of being in this state is $p_{\text {rup }}(t, \omega)$.

- Regulation-down: HPP power output decreases. GENCO earns on available regulation capacity $P_{r}(t, \omega)$ priced at $\pi_{r}(t, \omega)$, GENCO does not repay nor gets repaid for energy decreased priced at $\pi_{\text {spot }}(t, \omega)$ in a time period $t$ and a price scenario $\omega$. Probability of being in this state is $p_{\text {rdown }}(t, \omega)$.

- No-regulation: There is no change in HPP power output. GENCO earns on available regulation capacity $P_{r}(t, \omega)$ priced at $\pi_{r}(\mathrm{t}, \omega)$ in a time period $t$ and a price scenario $\omega$. Probability of being in this state is $1-p_{\text {rup }}(t, \omega)-p_{\text {rdown }}(t, \omega)$.

When GENCO commits in the 10 min spinning reserve DAM the following AGC states may occur:

- Reserve-up: HPP power output increases. GENCO earns on $10 \mathrm{~min}$ spinning reserve capacity $P_{S}(t, \omega)$ available for increase of power output priced at $\pi_{S}(t, \omega)$ in time period $t$ and price scenario $\omega$. Also GENCO earns on electricity produced for spinning reserve service $E_{s}(t)$ priced at $\pi_{\text {spot }}(t)$ in a time period $t$ and a price scenario $\omega$. Probability of being in this state is $p_{\text {del }}(t, \omega)$.

- Reserve-neutral: There is no change in HPP power output. GENCO earns on 10 min spinning reserve capacity $P_{S}(t, \omega)$ available for increase of power output priced at $\pi_{S}(\mathrm{t}, \omega)$ in a time period $t$ and a price scenario $\omega$. Probability of being in this state is $1-p_{\text {del }}(t, \omega)$.

The operating range of HPP when committed in the regulation and the $10 \mathrm{~min}$ spinning reserve DAM is defined with Equation (14) and is depicted in Figure 1b. A review of ancillary services models is available in [36-39]:

$$
\begin{gathered}
P_{e}(i, t, \omega) \leq P_{\max }(i)-P_{r}(i, t, \omega)-P_{s}(i, t, \omega) ; \kappa^{P_{\max }}(i, t, \omega) \\
P_{e}(i, t, \omega) \geq P_{0}(i)+P_{r}(i, t, \omega) ; v^{P_{0}}(i, t, \omega), \forall i \in I, \forall t \in T, \forall \omega \in \Omega
\end{gathered}
$$

For the regulation capacity $P_{r}(i, t, \omega)$, the value indicates the ability to move both up and down and requires both headroom and footroom, while provision of the spinning reserve $P_{S}(i, t, \omega)$ requires headroom but not footroom, meaning HPP cannot provide energy at its maximum output level but can run at minimum output level. Practical implementation of Equation (14) is shown in Equation (15) and is depicted in Figure 1: 


$$
\begin{gathered}
P_{e}(i, t, \omega) \leq P_{\max }(i)+\Delta_{1}(i) \cdot\left(d_{1}(i, t, \omega)-1\right) \\
+\Delta_{2}(i) \cdot\left(d_{2}(i, t, \omega)-1\right)+\Delta_{3}(i) \cdot\left(d_{3}(i, t, \omega)-1\right) \\
\left.+\Delta_{4}(i) \cdot\left(d_{4}(i, t, \omega)-1\right)\right)-P_{r}(i, t, \omega)-P_{s}(i, t, \omega) \\
P_{e}(i, t, \omega) \geq P 0_{5}(i)+\delta_{1}(i) \cdot\left(d_{1}(i, t, \omega)-1\right) \\
+\delta_{2}(i) \cdot\left(d_{2}(i, t, \omega)-1\right)+\delta_{3}(i) \cdot\left(d_{3}(i, t, \omega)-1\right) \\
+\delta_{4}(i) \cdot\left(d_{4}(i, t, \omega)-1\right)+P_{r}(i, t, \omega), \forall i \in I, \forall t \in T, \forall \omega \in \Omega
\end{gathered}
$$

Expected electricity produced when committed in the simultaneous energy, regulation and spinning reserve DAM in a time period $t$ and a price scenario $\omega$ Equation (16).

$$
\begin{gathered}
\mathbf{E}[E(i, t, \omega)]=E_{e}(i, t, \omega)+E_{r}(i, t, \omega)+E_{s}(i, t, \omega) \\
=P_{e}(i)+\left(p_{\text {rup }}(t, \omega)-p_{r \text { down }}(t, \omega)\right) \cdot P_{r}(i, t, \omega) \\
+p_{\text {del }}(t, \omega) \cdot P_{S}(i, t, \omega), \forall i \in I, \forall t \in T, \forall \omega \in \Omega
\end{gathered}
$$

Multiplying the ancillary service capacities $P_{r}(i, t, \omega)$ and $P_{S}(i, t, \omega)$ with the probabilities $p_{\text {del }}(t, \omega), p_{\text {rup }}(t, \omega)$ and $p_{\text {rdown }}(t, \omega)$ defines the energy produced for particular ancillary service in a time step $t$ and a price scenario $\omega$ Equations (18)-(20).

The probability matrix $p_{\mathrm{AGC}}(17)$ of size $\mathbb{R}^{T_{\max }} \times \mathbb{R}^{\Omega_{\max }}$ represents the probability of occurrence of the particular automatic generation control (AGC) state the Regulation-up state the Regulation-down state and the Reserve-up state for $\forall t \in T$ and $\forall \omega \in \Omega$. The matrix can be obtained statistically by a GENCO who has a history on offering ancillary services, whether they are committed obligatory, bilaterally or on the auction market, since this matrix is solely defined by technical features of frequency regulation zone:

$$
p_{\mathrm{AGC}}=\left(\begin{array}{ccccc}
p(1,1) & \cdots & p(1, \omega) & \cdots & p\left(1, \Omega_{\max }\right) \\
\vdots & \ddots & \vdots & \ddots & \vdots \\
p(t, 1) & \cdots & p(t, \omega) & \cdots & p\left(t, \Omega_{\max }\right) \\
\vdots & \ddots & \vdots & \ddots & \vdots \\
p\left(T_{\max }, 1\right) & \cdots & p\left(T_{\max }, \omega\right) & \cdots & p\left(T_{\max }, \Omega_{\max }\right)
\end{array}\right), \forall \text { AGC } \in\{\text { rup, rdown, del }\}
$$

Electricity produced for the energy market Equation (18):

$$
E_{e}(i, t, \omega)=P_{e}(i, t, \omega), \forall i \in I, \forall t \in T, \forall \omega \in \Omega
$$

Electricity produced for the regulation service Equation (19):

$$
E_{r}(i, t, \omega)=\left(p_{\text {rup }}(t, \omega)-p_{\text {rdown }}(t, \omega)\right) \cdot P_{r}(i, t, \omega), \forall i \in I, \forall t \in T, \forall \omega \in \Omega
$$

Electricity produced for the spinning reserve service Equation (20):

$$
E_{S}(i, t, \omega)=p_{\text {del }}(t, \omega) \cdot P_{S}(i, t, \omega), \forall i \in I, \forall t \in T, \forall \omega \in \Omega
$$

Expected electricity produced is equal to the performance curve Equations (3)-(12) in all time intervals Equation (21):

$$
\mathbf{E}[E(i, t, \omega)]=P(i, t, \omega), \forall i \in I, \forall t \in T, \forall \omega \in \Omega
$$

Ramp rate limits Equation (22):

$$
\begin{gathered}
P(i, t, \omega)-P(i, t-1, \omega) \leq U P(i) \\
P(i, t-1, \omega)-P(i, t, \omega) \leq D R(i), \forall i \in I, \forall t \in T, \forall \omega \in \Omega
\end{gathered}
$$


The maximum regulation capacity that can be offered is calculated as the MSR times five min Equation (23). The 10 min spinning capacity is defined as the MSR times ten min Equation (24).

$$
\begin{gathered}
0 \leq P_{r}(i, t, \omega) \leq 5 \times \operatorname{MSR}(i), \forall i \in I, \forall t \in T, \forall \omega \in \Omega \\
0 \leq P_{S}(i, t, \omega) \leq 10 \times \operatorname{MSR}(i), \forall i \in I, \forall t \in T, \forall \omega \in \Omega
\end{gathered}
$$

\subsection{Random Variable: Energy and Ancillary Services MCPS}

The set $\Omega$ will represent future states of knowledge, and the single element $\omega$ will define a one future state, meaning $\omega \in \Omega$. The set $\Omega$ will have a mathematical structure of probability space with probability measure $p$ for comparing the likelihood of the future states $\omega$.

The discrete random variable $\pi$ as shown in Equation (25) will represent random daily price series, and is defined with $\Pi: \Omega \rightarrow A$, where $A \subseteq \mathbb{R}^{T_{\max }}$, since probability won't be defined on each element of $\mathbb{R}^{T_{\text {max }}}$ vector space.

The probability of particular daily price scenario of market $m \Pi_{\mathrm{m}}(\omega) \in A$ is defined as Equation (26):

$$
\begin{gathered}
\Pi_{m}=\left(\begin{array}{lllll}
\pi(1) & \cdots & \pi(\omega) & \cdots & \pi\left(\Omega_{\max }\right) \\
p(1) & \cdots & p(\omega) & \cdots & p\left(\Omega_{\max }\right)
\end{array}\right), \forall m \in\{e, r, s, \text { spot }\} \\
\text { where, }\left\{\omega \in \Omega: \Pi_{m}(\omega)=\left(\pi(1), \ldots, \pi(t), \ldots, \pi\left(T_{\max }\right)\right)\right\}, \forall m \in\{e, r, s, \text { spot }\} \\
p\left\{\Pi_{m}(\omega)\right\}=P\left(\omega \in \Omega: \Pi_{m}(\omega) \in A\right)=p(\omega), \forall m \in\{e, r, s, \operatorname{spot}\}
\end{gathered}
$$

Finite number of future states are observed, $\omega \in \Omega \subseteq \mathbb{N}$. The random variable Equation (25) is defined for energy and ancillary service DAM. Moreover, it can be shown that the distribution of hourly prices is approximately lognormal [33]. Thus resulting random variable $\Pi_{m}$ is defined for the each time step $t$ separately Equation (27):

$$
\Pi_{m}=\left(\begin{array}{lllll}
\pi(t, 1) & \cdots & \pi(t, \omega) & \cdots & \pi\left(t, \Omega_{\text {max }}\right) \\
p(t, 1) & \cdots & p(t, \omega) & \cdots & p\left(t, \Omega_{\text {max }}\right)
\end{array}\right), \forall m \in\{e, r, s, \text { spot }\}
$$

\subsection{Risk Measure}

An easy way to incorporate a risk into linear model is to use CVaR [16] as a measure of risk. $\beta-\mathrm{CVaR}$ is defined as an average loss of a $1-\beta$ worst scenarios, thus called tail loss (Figure 2a). $\alpha-\mathrm{CVaR}$ (Figure $2 \mathrm{~b}$ ) is an average profit in worst $1-\alpha$ (i.e., $15 \%$ ) scenarios and $\alpha-\mathrm{VaR}$ is minimal profit which GENCO can expect in rest $\alpha$ (i.e., $85 \%$ ) scenarios.

Figure 2. The hypothetical probability density function (PDF) of a (a) loss; (b) profit.

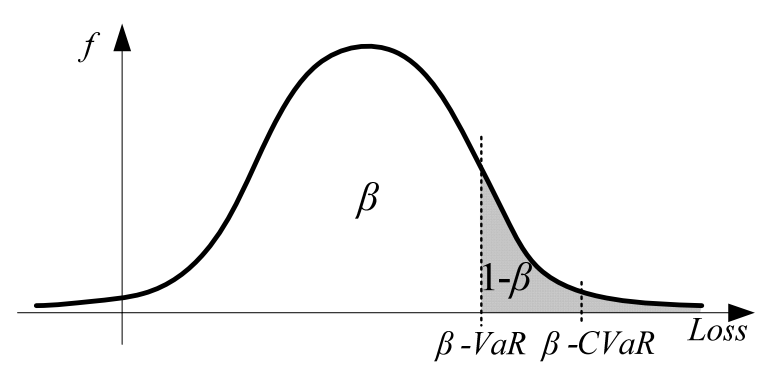

(a)

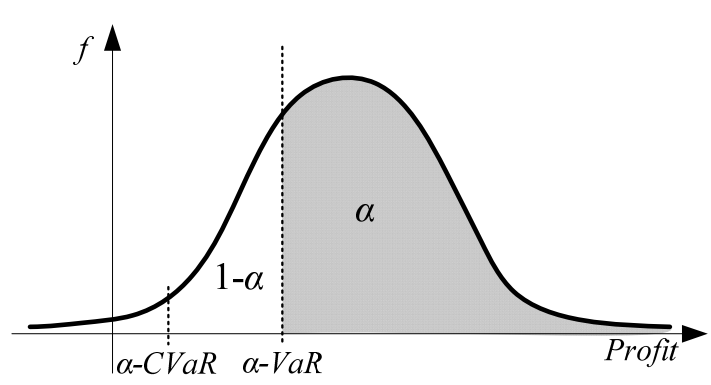

(b) 
$\mathrm{CVaR}$ is a coherent measure of risk, meaning CVaR has properties of convexity, monotonicity, closedness, positive homogeneity, subadditivity and translation invariance [20-23]. In the next section $\alpha-\mathrm{VaR}$ and $\alpha-\mathrm{CVaR}$ are formulated using the profit PDF as depicted in Figure $2 \mathrm{~b}$.

Both $\alpha-\mathrm{VaR}$ and $\alpha-\mathrm{CVaR}$ can be calculated by solving an elementary optimization problem of convex type in one dimension. For this purpose the special function Equation (28) is formulated:

$$
\begin{gathered}
F_{\alpha}(\text { Variables, } \zeta)=\zeta-\frac{1}{1-\alpha} \sum_{\omega=1}^{\Omega_{\max }} p(\omega) \cdot\left[\zeta-\sum_{t=1}^{T} \operatorname{Profit}(t, \omega)\right]^{+} \\
\text {where, }\left[\zeta-\sum_{t=1}^{T} \operatorname{Profit}(t, \omega)\right]^{+}=\max \left\{0, \zeta-\sum_{t=1}^{T} \operatorname{Profit}(t, \omega)\right\}
\end{gathered}
$$

When maximizing Equation (29) over all variables defined in the model, Equations (30) and (31) are obtained:

$$
\begin{gathered}
\max _{(\text {Variables }, \zeta) \in \mathbb{R}^{\text {No.of var }} \times \mathbb{R}} F_{\alpha}(\text { Variables }, \zeta) \\
\alpha-\mathrm{CVaR}=F_{\alpha}\left(\text { Variables }^{*}, \zeta^{*}\right) \\
\alpha-\operatorname{VaR}=\zeta^{*}
\end{gathered}
$$

where the Variables denotes all the variables defined in nomenclature. The variable $\zeta$ is shown separately only to point out its importance. In Equations (28)-(31) a risk measure is expressed as a daily value.

Generally, when the daily CVaR is used, the risk will average out throughout the day, and this is not desirable as, especially in a case of a major contingency in particular hour-this can result in unpredictable values of the daily CVaR. Consequently, the hourly $\alpha-\operatorname{VaR}(t)$ and the hourly $\alpha-\operatorname{CVaR}(t)$ are formulated using the hourly special function $F_{\alpha}\left(\right.$ Variables $\left._{t}, \zeta(t)\right)$ over all $\left(\right.$ Variables $\left._{t}, \zeta(t)\right) \in$ $\mathbb{R}^{\text {No.of var in step } t} \times \mathbb{R}$.

Since objective function is already defined, the special function is thus brought in the optimization problem in a form of the constraint Equation (32):

$$
F_{\alpha}\left(\operatorname{Variables}_{t}, \zeta(t)\right) \geq \operatorname{minCVaR}(t) \forall t \in T
$$

where the Variables $_{t}$ denotes all the variables defined in nomenclature in a time step $t$. The variable $\zeta(t)$ is the hourly value.

When implementing the constraint Equation (32), the risk is "shaped" using the profit tolerance $\operatorname{minCVaR}(t) \forall t \in T$. When the set of profit tolerances $\operatorname{minCVaR}(n, t), \forall n \in N$ is introduced in the optimization model and the requirement Equation (33) is valid, then Equations (34)-(36) is used to shape the risk with CVaR (Figure 3):

$$
\operatorname{minCVaR}(n-1, t)<\operatorname{minCVaR}(n, t)<\operatorname{minCVaR}(n+1, t) \forall t \in T, \forall n \in N
$$

The linear formulation of Equation (32), defined using indexed assignment is used in the model Equations (34)-(36):

$$
\begin{gathered}
\eta(t, \omega) \geq 0 \forall t \in T, \forall \omega \in \Omega \\
\eta(t, \omega) \geq \operatorname{Profit}(t, \omega)-\zeta(t) \forall t \in T, \forall \omega \in \Omega
\end{gathered}
$$




$$
\zeta(t)-\frac{1}{1-\alpha} \sum_{\omega=1}^{\Omega_{\max }} p(\omega) \cdot \eta(t, \omega) \geq \operatorname{minCVaR}(n, t) \forall t \in T
$$

Figure 3. Algorithm for risk-shaping with CVaR.

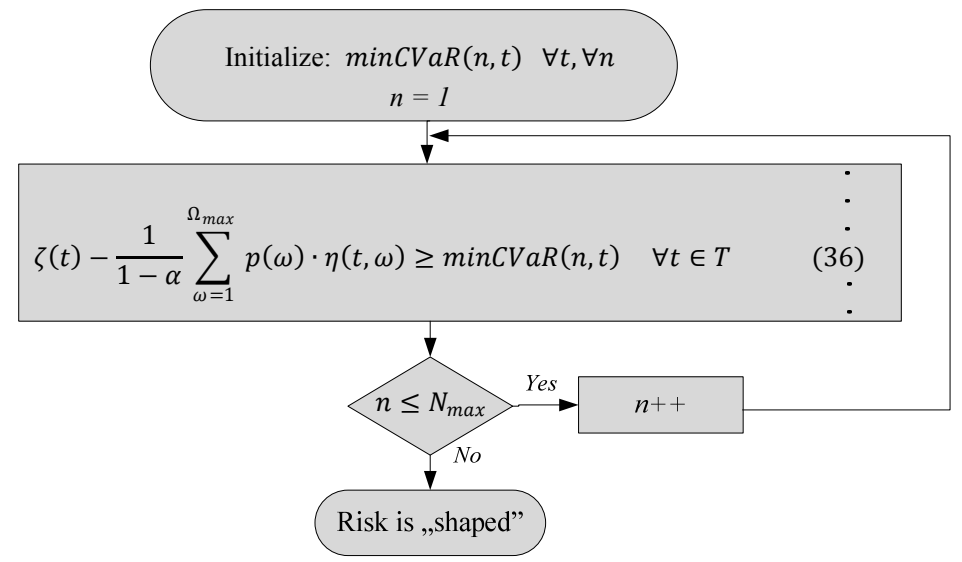

\subsection{Objective Function}

GENCO's objective function is maximal expected profit (37). GENCO can justify optimization of the expected profit by the law of large numbers because it gives an optimal decision on average. However, because of the variability of the input data, the average of the first few results may be very bad and it does not help that the decisions were optimal on average. For these reasons, quantitative models of risk and risk aversion are needed.

GENCO's profit in a time step $t$ of a price scenario $\omega(37)$ :

$$
\begin{gathered}
\operatorname{Profit}(t, \omega)=\sum_{i \in I}\left[\Pi_{e}(t, \omega) \cdot E_{e}(i, t, \omega)+\Pi_{\mathrm{spot}}(t, \omega) \cdot E_{r}(i, t, \omega)+\Pi_{r}(t, \omega) \cdot P_{r}(i, t, \omega)\right. \\
\left.+\Pi_{\mathrm{spot}}(t, \omega) \cdot E_{s}(i, t, \omega)+\Pi_{s}(t, \omega) \cdot P_{s}(i, t, \omega)\right]
\end{gathered}
$$

Objective function is an expected profit of the planning horizon $T_{\max }$ Equation (38):

$$
\text { Profit }=\sum_{\omega=1}^{\Omega} p(\omega) \cdot \sum_{t=1}^{T} \operatorname{Profit}(t, \omega)
$$

\subsection{Pricing of Energy and Ancillary Services}

Shadow prices of the HERBM constrains are analyzed Equation (39). Shadow price represents change per unit of constraint, in the objective value of the optimal solution, i.e., marginal utility when relaxing constraints by a unit value or marginal cost when strengthening a constraint:

$$
\left(\kappa^{X_{\max }}(i, t, \omega), v^{X_{\min }}(i, t, \omega) ; \kappa^{P_{\max }}(i, t, \omega), v^{P_{0}}(i, t, \omega) ; \psi(i, t, \omega), \lambda(i, \omega)\right)
$$

The shadow prices Equation (40) are paired with the parameter unit change Equation (40) of the right-hand side (r.h.s.) of the constraints Equations (2), (14) and (42):

$$
\left(\Delta X_{\max }(i, t, \omega),-\Delta X_{\min }(i, t, \omega) ; \Delta P_{\max }(i, t, \omega),-\Delta P_{0}(i, t, \omega) ; \Delta W(i, t, \omega), \Delta \zeta(i, \omega)\right)
$$

The Shadow price of used water Equation (41): 


$$
\psi(i, t, \omega)=\lambda(i, \omega)+\kappa^{X_{\max }}(i, t, \omega)-v^{X_{\min }}(i, t, \omega)
$$

The shadow price of used water $\psi(i, t, \omega)$ can also be represented by a change in the objective value, per unit change of the reservoir $i$ water inflow $\Delta W(i, t, \omega)$ in a time step $t$ and a scenario $\omega$. Then the amount of $\Delta W(i, t, \omega)$ won't be available in the other hours of scenario $\omega$ [9]. In order to determine the marginal cost of water, the standard profit-maximizing operation problem needs to be formulated [9,10] thus Equation (42):

$$
\sum_{t=1}^{T_{\max }}(q(i, t, \omega)-W(i, t, \omega)) \leq 0 ; \lambda(i, \omega)
$$

Since the water shadow price $\psi(i, t, \omega)$ is in $\left(\frac{\$}{\mathrm{~m}^{3}}\right)$ it needs to be converted in (\$/MWh). In order to do that conversion, coefficient $\rho^{-1}(i, t, \omega)$ is formulated to evaluate energy potential of the reservoir $i$ in a time step $t$ and a price scenario $\omega$. After simulation is ended Equation (43) is obtained:

$$
\rho^{-1}(i, t, \omega)=M \cdot \frac{q(i, t, \omega)}{P(i, t, \omega)}
$$

The pairs Equations (44)-(46) are obtained for every time step $t$ and a price scenario $\omega$. The available water is redistributed according to rule Equation (16) consequently the energy is priced as Equation (44), the regulation as Equation (45) and the 10 min spinning reserve as Equation (46) for every time step $t$ and the scenario $\omega$. Afterword's for the each time step $t$ pairs Equations (44)-(46) are ordered in ascending order according to the prices of the set $\Omega$ (Figure 4):

$$
\begin{gathered}
\left(P_{e}(i, t, \omega), 1-p_{\text {del }}(i, t, \omega)-\left(p_{\text {rup }}(i, t, \omega)-p_{\text {rdown }}(i, t, \omega)\right) \cdot \rho^{-1}(i, t, \omega) \cdot \psi(i, t, \omega)\right) \\
\left(P_{r}(i, t, \omega),\left(p_{\text {rup }}(i, t, \omega)-p_{\text {rdown }}(i, t, \omega)\right) \cdot \rho^{-1}(i, t, \omega) \cdot \psi(i, t, \omega)\right) \\
\left(P_{S}(i, t, \omega), p_{\text {del }}(i, t, \omega) \cdot \rho^{-1}(i, t, \omega) \cdot \psi(i, t, \omega)\right)
\end{gathered}
$$

Water shadow price of one additional $\left(\mathrm{m}^{3}\right)$ of water in particular hour, and one $\left(\mathrm{m}^{3}\right)$ reduced from all other hours, as said represents marginal cost of producing one more $\left(\mathrm{m}^{3}\right)$ or $(\mathrm{MWh})$ so it is particularly convenient to use for creating a bid curve. An ancillary service DAM is another opportunity for GENCO to increase profit and it generates additional opportunity costs which are reflected as an increase of water shadow prices.

Figure 4. Hypothetical bid curve for 10 min spinning reserve DAM of hour $t$.

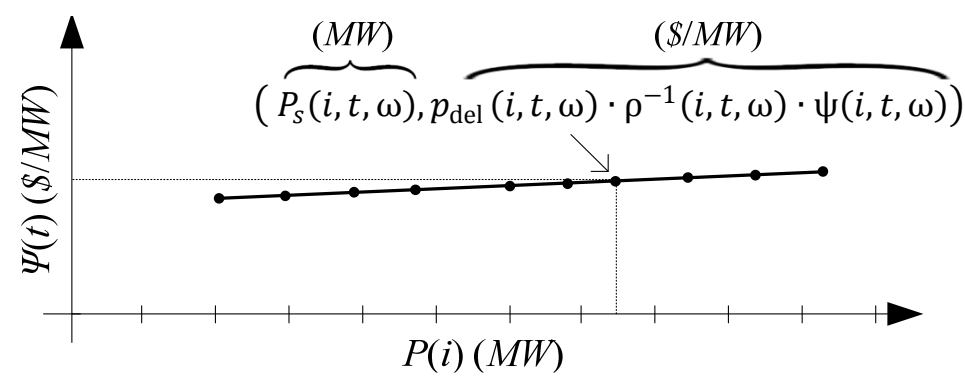

The approach for pricing energy and ancillary services is depicted on Figure 5 using flow diagram form to indicate necessary steps of the approach with reference indicating the mathematical expressions used to accomplish each step. The model is defined as a MILP problem using indexed 
assignments. The presented results were obtained on $3.4 \mathrm{GHz}$ based processor with $8 \mathrm{~GB}$ RAM using CPLEX (International Business Machines Corporation, New York, NY, USA) under General Algebraic Modeling System (GAMS) [40]. However, in general terms, using the dual information from a mixed integer programming problem may not capture all the terms in the problem related to the binary variables. The Case Study in this research is considered fairly accurate, since optimality tolerance is set to $0 \%$. This means that the solver will stop when it finds a feasible integer solution within $0 \%$ of the global optimum.

Figure 5. The approach for pricing energy and ancillary services.

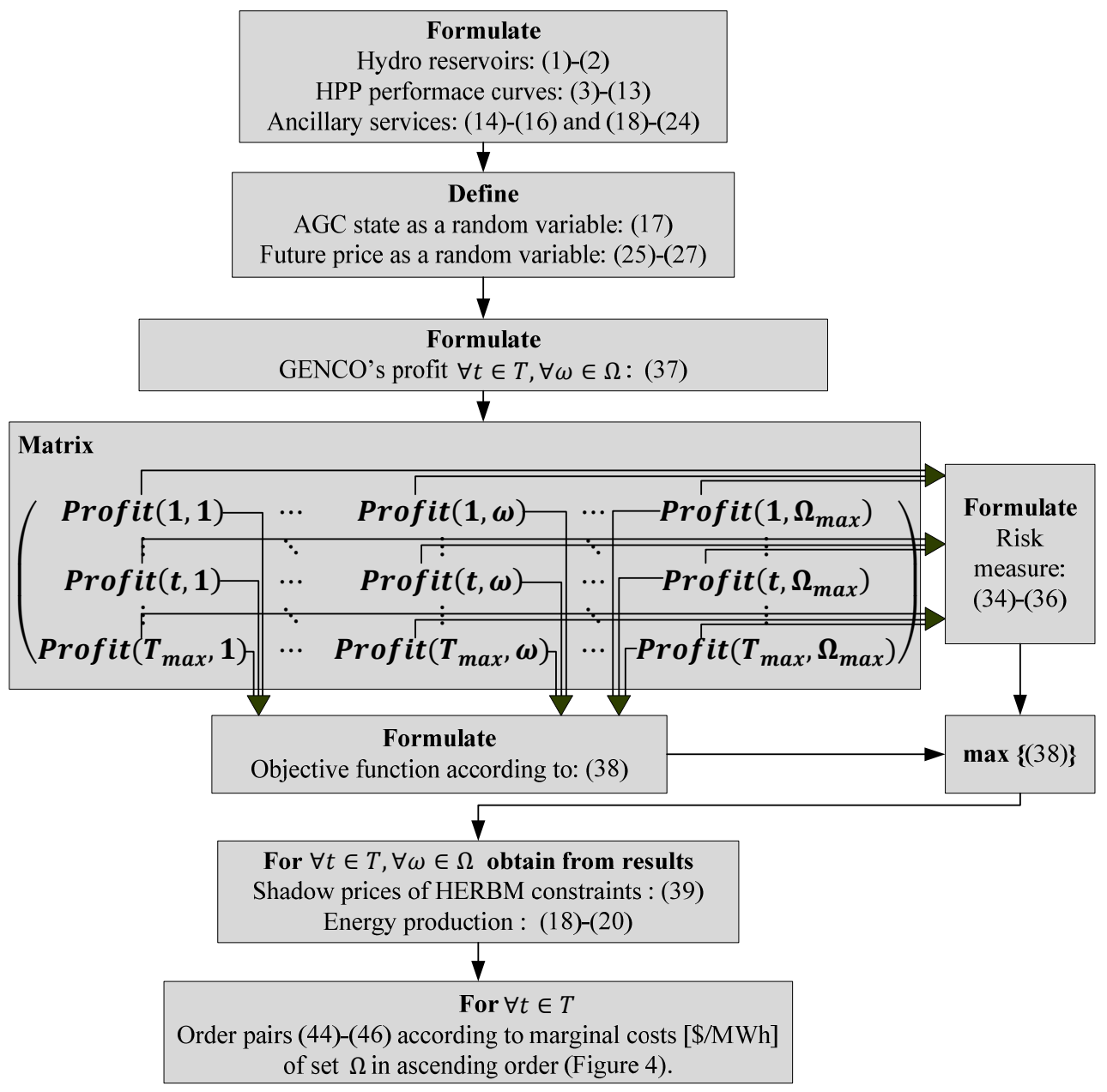

\section{Example and Results}

For the needs of this research HPS Vinodol (Croatia) is modeled, which consists of: four reservoirs, one pump station (PS), two pump storage hydropower plants (PSP) and one HPP (Table 1) (Figure 6). Real HPS Vinodol is already used for frequency regulation ancillary services. Price-taker model is considered reasonably accurate since of relatively small size of HPS Vinodol compared to other participants on DAM assumed in this research. 
Table 1. HPS Vinodol facilities parameters.

\begin{tabular}{cccccc}
\hline Reservoir & $\boldsymbol{X}_{\max }\left(\mathbf{m}^{3}\right)$ & $\boldsymbol{W}\left(\mathbf{m}^{\mathbf{3}} / \mathbf{s}\right)$ & Power Plant & $\boldsymbol{Q}_{\max }(\mathbf{M W})$ & $\boldsymbol{P}_{\max }(\mathbf{M W})$ \\
\hline Križ & $0.06 \times 10^{6}$ & 3 & PS Križ & 1.1 & 0.34 \\
Lokve & $34.8 \times 10^{6}$ & 3 & PSP Fužine & $10 / 9$ & $4.6 / 4.8$ \\
Bajer & $1.32 \times 10^{6}$ & 3 & HPP Vinodol & 18.6 & 94.5 \\
Lepenica & $4.26 \times 10^{6}$ & 3 & PSP Lepenica & $6.2 / 5.3$ & $1.14 / 1.25$ \\
\hline
\end{tabular}

Figure 6. HPS Vinodol.

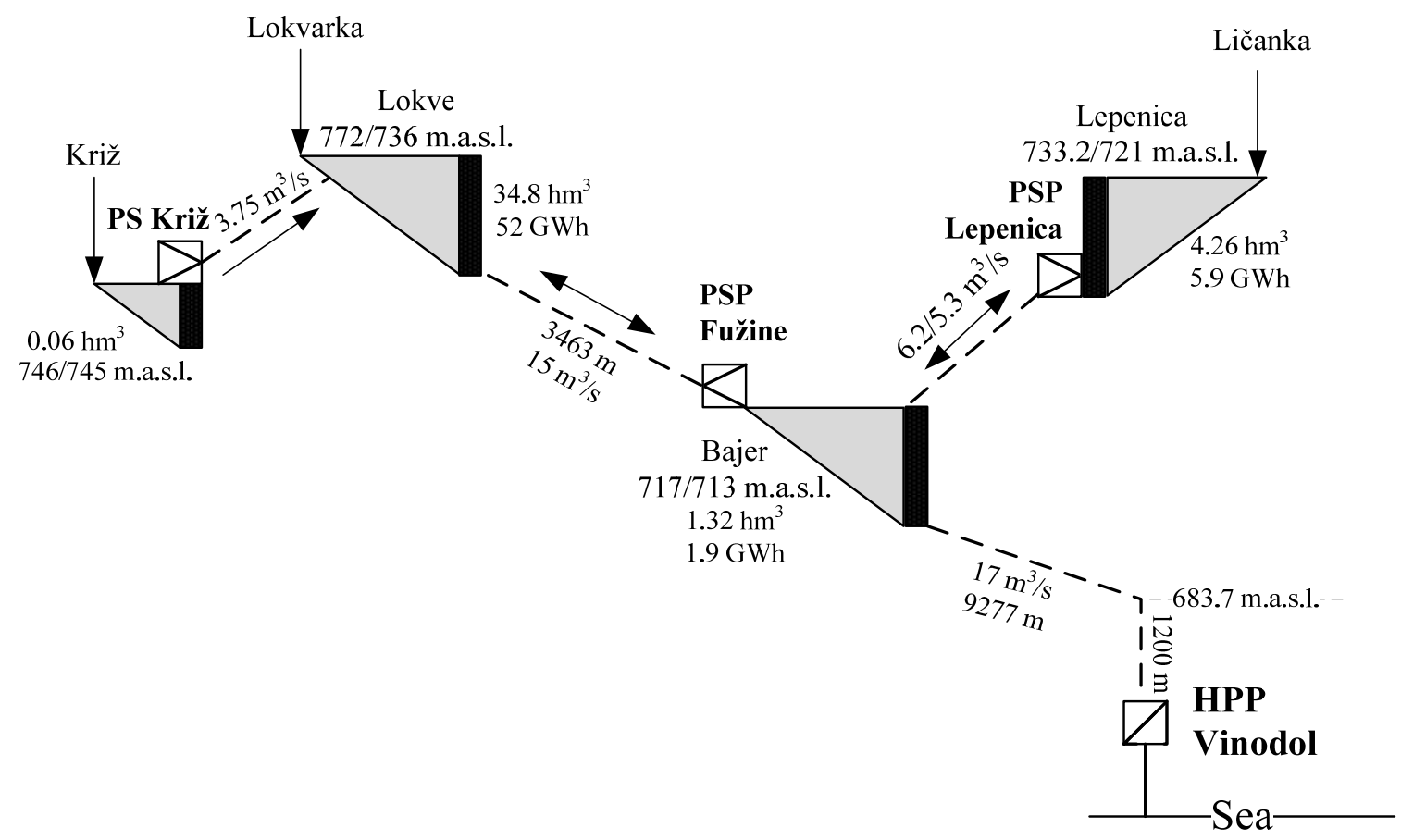

The prices are formulated according to Equation (27) where values are normally distributed. Mean and standard deviation of prices in each time step $t$ are statistically obtained according to Equations (47) and (48):

$$
\begin{gathered}
\mu(t)=\frac{1}{Q_{\max }} \sum_{\omega=1}^{\Omega_{\max }} \pi(t, \omega) \\
\sigma(t)=\sqrt{\frac{1}{\Omega_{\max }} \sum_{\omega=1}^{\Omega_{\max }}(\pi(t, \omega)-\mu(t))^{2}}
\end{gathered}
$$

The energy and ancillary services prices are obtained from New York DAM [34], from 3 January 2011 to 5 December 2011 (337 days are observed) and descriptive statistics are calculated (Table 2). Using pseudo-random number sampling and obtained descriptive statistics ten price scenarios $\left(\Omega_{\max }=10\right)$ are generated for each hour (Figure 7$)$. The probability of occurrence $p(t, \omega)$ of the each scenario $\omega$ in the hour $t$ is $1 / \Omega_{\max }$.

Observed GENCO owns HPS Vinodol. For clarity and computational effectiveness HPP Vinodol profit is maximized while rest of HPS is used for that objective. There is no significant lose in accuracy when having in mind that in GENCO's profit, HPP Vinodol profit participates with 95\% or 
more. Probabilities are considered stationary, $p_{e}$ is $100 \%, p_{\text {del }}$ is $3 \%, p_{\text {rup }}$ and $p_{\text {rdown }}$ are $40 \%$ and $35 \%$ respectively [35]. The confidence level $\alpha$ is set to 0.85 . Having in mind ancillary services requirements [41,42] and the HPP Vinodol ramp rate limits (Table 3) the problem is considered sufficiently accurate. The ramp rate limits of HPP Vinodol are as follows; MSR(up) is $255.15 \mathrm{MW} / \mathrm{min}$, MSR(down) is $340.2 \mathrm{MW} / \mathrm{min}$, ramping capabilities UR and DR between hours is $94.2 \mathrm{MW} / \mathrm{h}$. The profit tolerances are $\operatorname{minCVaR}(1, t)=0, \operatorname{minCVaR}(2, t)=400, \operatorname{minCVaR}(3, t)=800$, and $\operatorname{minCVaR}(4, t)=1380$ for every $t$.

Table 2. Descriptive statistics of NYISO prices in (\$/MWh).

\begin{tabular}{|c|c|c|c|c|c|c|c|c|c|c|c|c|c|}
\hline \multirow{2}{*}{ h } & \multicolumn{2}{|c|}{ Energy } & \multicolumn{2}{|c|}{ Regulation } & \multicolumn{2}{|c|}{ 10-min } & & \multicolumn{2}{|c|}{ Energy } & \multicolumn{2}{|c|}{ Regulation } & \multicolumn{2}{|c|}{ 10-min } \\
\hline & $\mu$ & $\sigma$ & $\boldsymbol{\mu}$ & $\sigma$ & $\boldsymbol{\mu}$ & $\sigma$ & & $\mu$ & $\sigma$ & $\mu$ & $\sigma$ & $\mu$ & $\sigma$ \\
\hline 1 & 39.8 & 13.0 & 9 & 3.0 & 4.8 & 0.3 & 13 & 64.6 & 26.6 & 9.8 & 0.8 & 8.9 & 2.2 \\
\hline 2 & 36.2 & 11.4 & 5.3 & & 4.7 & 0.5 & 14 & & & & & 10.2 & 2.0 \\
\hline 3 & 34.6 & 10.9 & 5.3 & 0.4 & 4.2 & 0.4 & 15 & 67.6 & 33.2 & 10.4 & 1.6 & 11.2 & 2.5 \\
\hline 4 & 34.5 & 10.8 & 4.8 & 0.4 & 4.7 & 0.4 & 16 & 68.4 & 34 & 11.0 & 1.7 & 10.4 & 2.3 \\
\hline 5 & 36.5 & 10.4 & 8.9 & 2. & 4.5 & 0.4 & 17 & 67.2 & 30 & 12.9 & & 13.9 & 2. \\
\hline 6 & 41.5 & 11.7 & 18.1 & 6.9 & 4.6 & 0.5 & 18 & 68.1 & 27.8 & 11.3 & 2.1 & 10.1 & 2.6 \\
\hline 7 & 48.2 & 15.9 & & 4. & 6.1 & 1.1 & 19 & 67.4 & & 10.8 & & 9. & 2.1 \\
\hline 8 & 52.5 & 17.8 & 12.1 & 3.1 & 8.9 & 0.7 & 20 & 64.1 & 21 & 10.3 & 0.8 & 9. & 1.1 \\
\hline 9 & 55.6 & 17.8 & 13.3 & 3.2 & 9.0 & 0.4 & 21 & .2 & 20 & 10.4 & 1.2 & 10.1 & 1.2 \\
\hline 10 & 59.2 & 19.5 & 10.0 & 0.0 & 8.5 & 0.4 & 22 & 51.5 & 17.5 & 11.4 & 1.1 & 11.0 & 1.1 \\
\hline 11 & 61.7 & 21.5 & 10.0 & 0.1 & 9.4 & 0.6 & 23 & 46.1 & 14.9 & 10.7 & 1.6 & 6.4 & 1.3 \\
\hline 12 & 62.8 & 22.9 & 11.1 & 1.0 & 9.9 & 1.1 & 24 & 43.7 & 14.5 & 10.3 & 1.8 & 5.0 & 0.0 \\
\hline
\end{tabular}

Figure 7. Randomly generated daily price scenarios for the energy DAM.

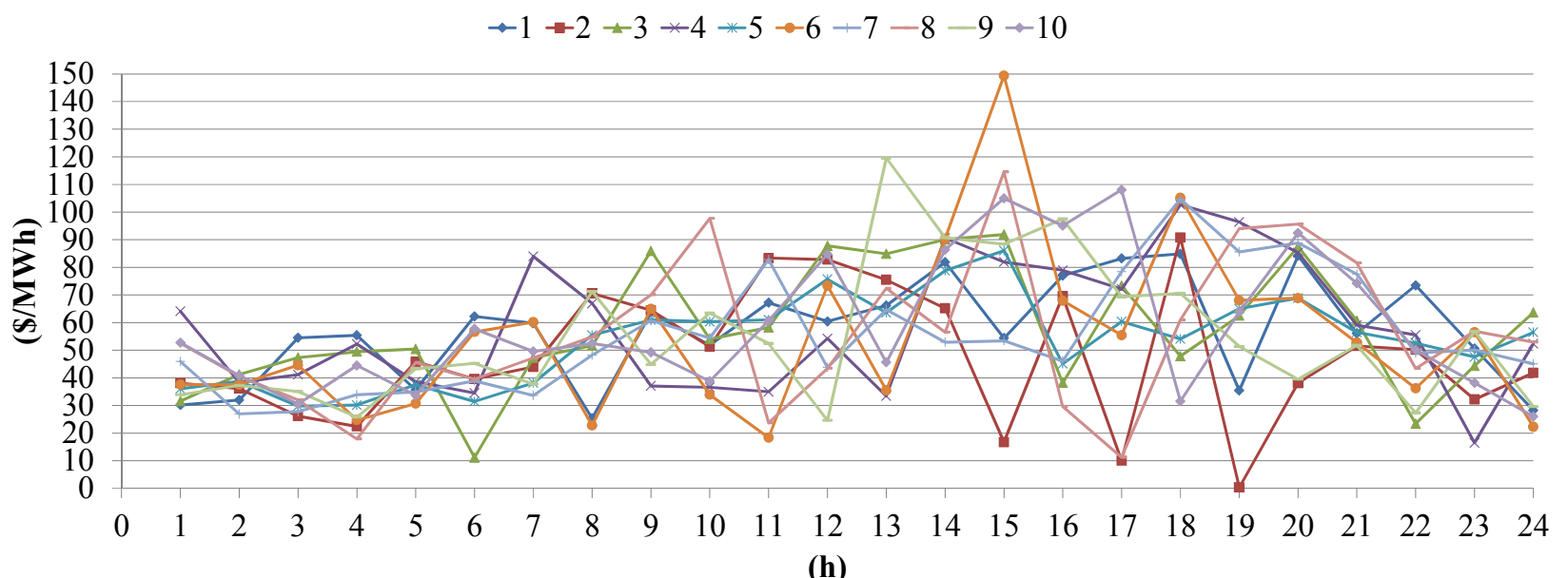

Table 3. Daily profit and daily risk measures $\alpha-C V a R$ and $\alpha-V a R$ for confidence level $\alpha=0,85$ expressed in dependence of hourly $\alpha-\mathrm{CVaR}(t)$.

\begin{tabular}{cccc}
\hline $\boldsymbol{\alpha}-\mathbf{C V a R}(\boldsymbol{t})$ & Profit & $\boldsymbol{\alpha}$-CVaR & $\boldsymbol{\alpha}$-VaR \\
\hline 0 & 98,193 & 0 & 0 \\
400 & 97,838 & 9,600 & 14,400 \\
800 & 98,162 & 19,100 & 28,500 \\
1,380 & 96,959 & 33,120 & 44,037 \\
\hline
\end{tabular}


The perfectly inelastic (vertical) energy marginal cost curves here considered as bid curves are obtained for the ordinate values $38 \mathrm{MWh}$ and $57 \mathrm{MWh}$ (Figure 8). For the price threshold $\$ 0$ and $\$ 1380$ the mean shadow prices are $\$ 1.9$ and $\$ 2.4$, respectively. This means reducing risk costs, and these costs can be determined.

Figure 8. The marginal cost curves for energy production for profit tolerances (a) $\operatorname{minCVaR}(1, t)=0 ;$ (b) $\operatorname{minCVaR}(2, t)=400 ;$ (c) $\operatorname{minCVaR}(3, t)=800$; (d) $\operatorname{minCVaR}(4, t)=1380$.

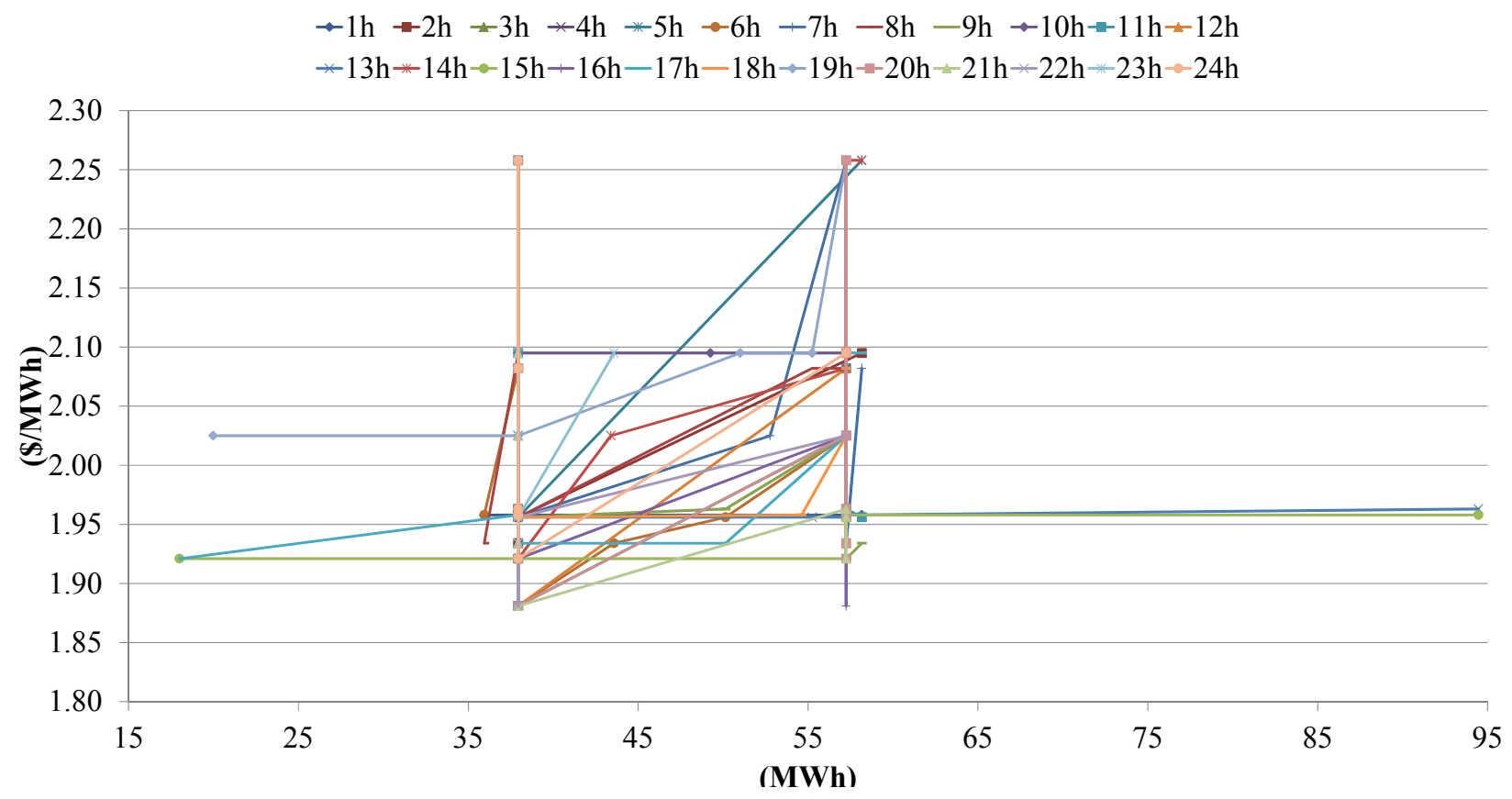

(a)

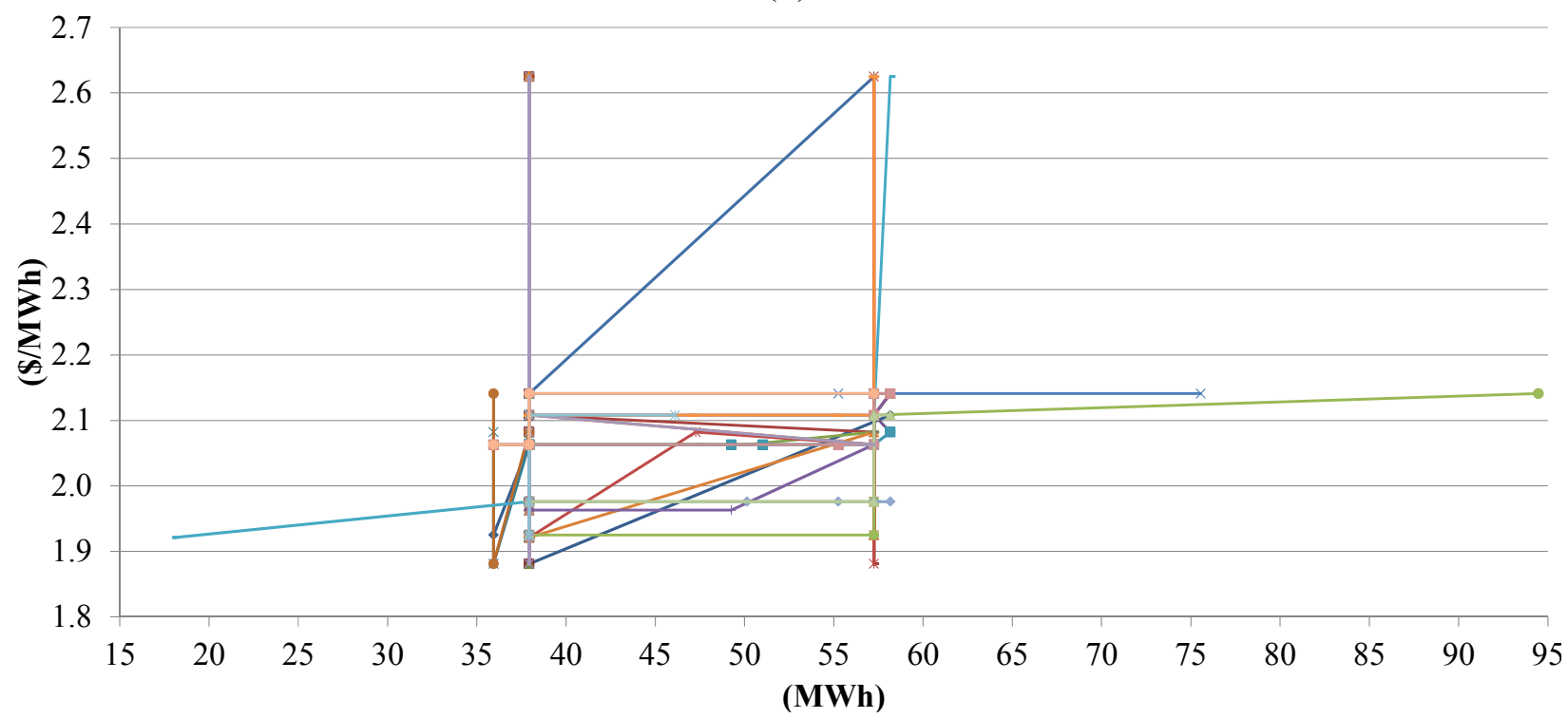

(b) 
Figure 8. Cont.

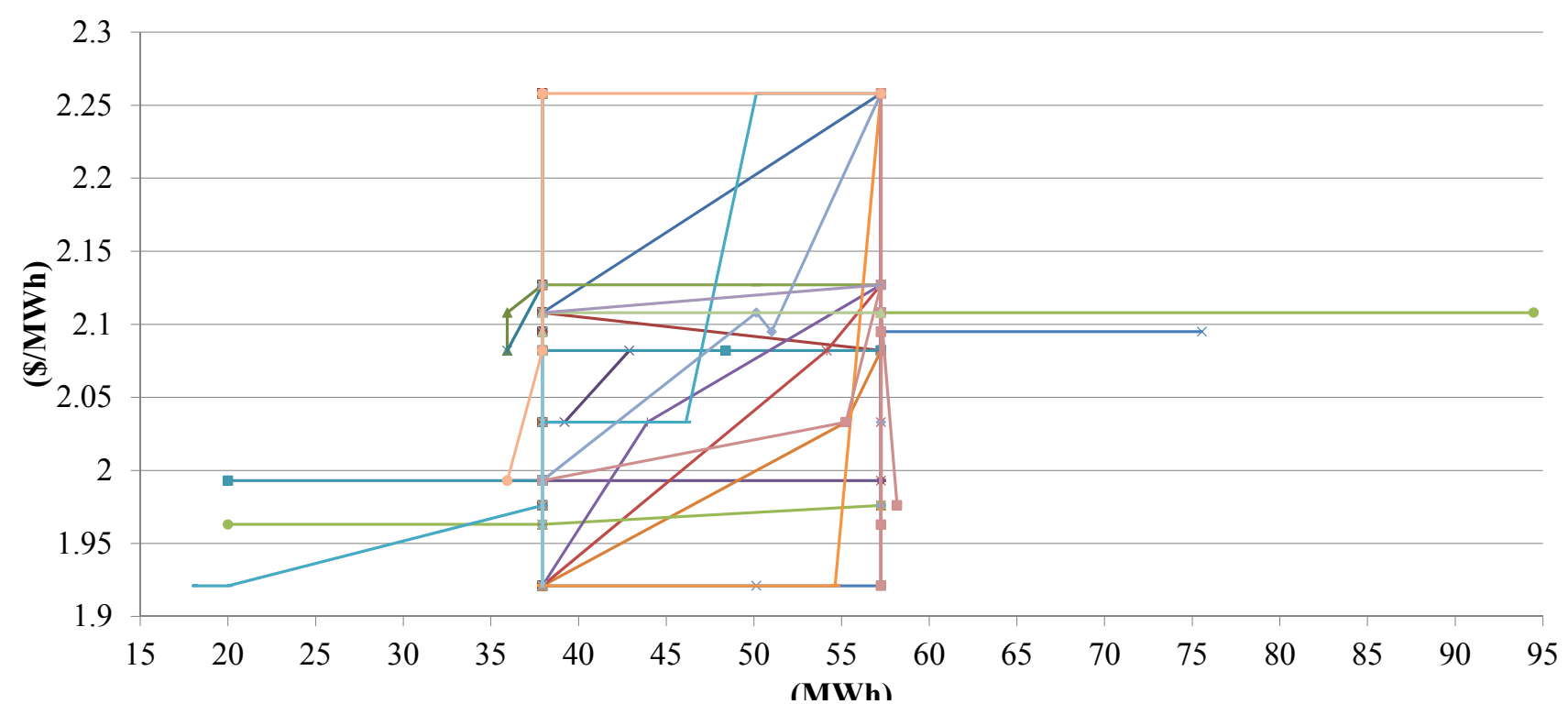

(c)

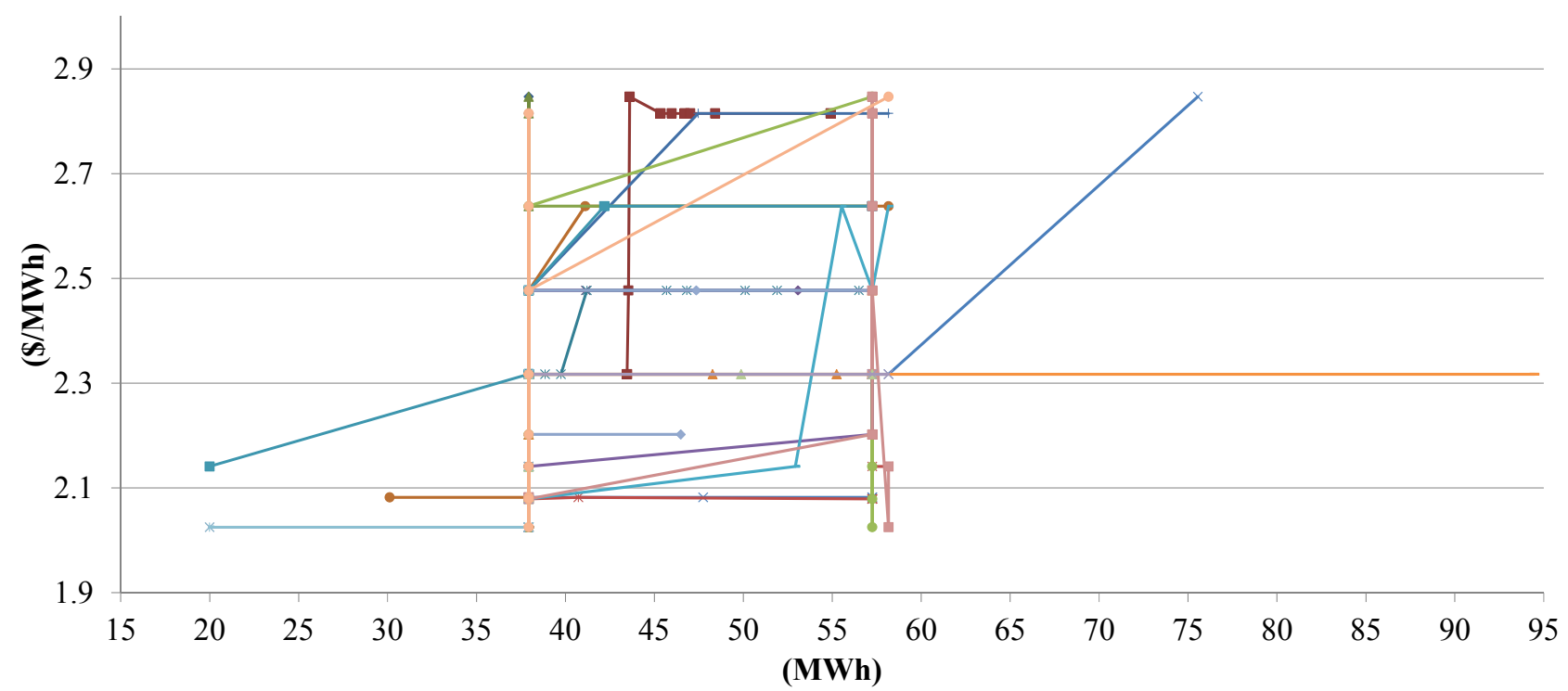

(d)

For the regulation DAM (Figure 9), the perfectly inelastic bid curves are obtained for 18 MW and $37 \mathrm{MW}$ and at the same points all other bid curves are ending, reason for this is regulation headroom and footroom. For the price threshold $\$ 0$ and $\$ 1^{\prime} 380$ the mean shadow prices are $\$ 0.11$ and $\$ 0.135$, respectively.

For spinning reserve DAM (Figure 10), most of the bid curves are perfectly inelastic and located around $38 \mathrm{MW}$. Optimization showed that GENCO should seek to bid certain amount of capacity. When the price threshold increases from $\$ 0$ to $\$ 1380$ the mean spinning reserve prices are $\$ 0.065$ and $\$ 0.075$, respectively.

The water shadow prices have relatively low deviation compared to DAM prices and in this research use of the simplified approach with the constant water shadow prices over the planning horizon is justified. The hourly water shadow prices also have relatively low mean value which is a result of having more than enough water with relative relationships maintained so conclusions can be 
given (e.g., ratio between energy and ancillary services bid prices is similar to the ratio between energy and ancillary services DAM prices). The results were not obtained for lesser amount of water to avoid long computation time. Further bid curve analysis is omitted in this work since its slope, ordinate and aspics position is highly determined by input parameters.

Figure 9. The marginal cost curves for regulation for the profit tolerances for
(a) $\operatorname{minCVaR}(t)=0$;
(b) $\operatorname{minCVaR}(t)=400$;
(c) $\operatorname{minCVaR}(t)=800$;

(d) $\min \operatorname{CVaR}(t)=1380$.

$$
\begin{aligned}
& \rightarrow 1 h-2 h-3 h * 4 h * 5 h \rightarrow 6 h+7 h-8 h-9 h \rightarrow 10 h-11 h-12 h \\
& * 13 h * 14 h \rightarrow-15 h+16 h-17 h-18 h \rightarrow 19 h-20 h \rightarrow 21 h * 22 h * 23 h \rightarrow-24 h
\end{aligned}
$$

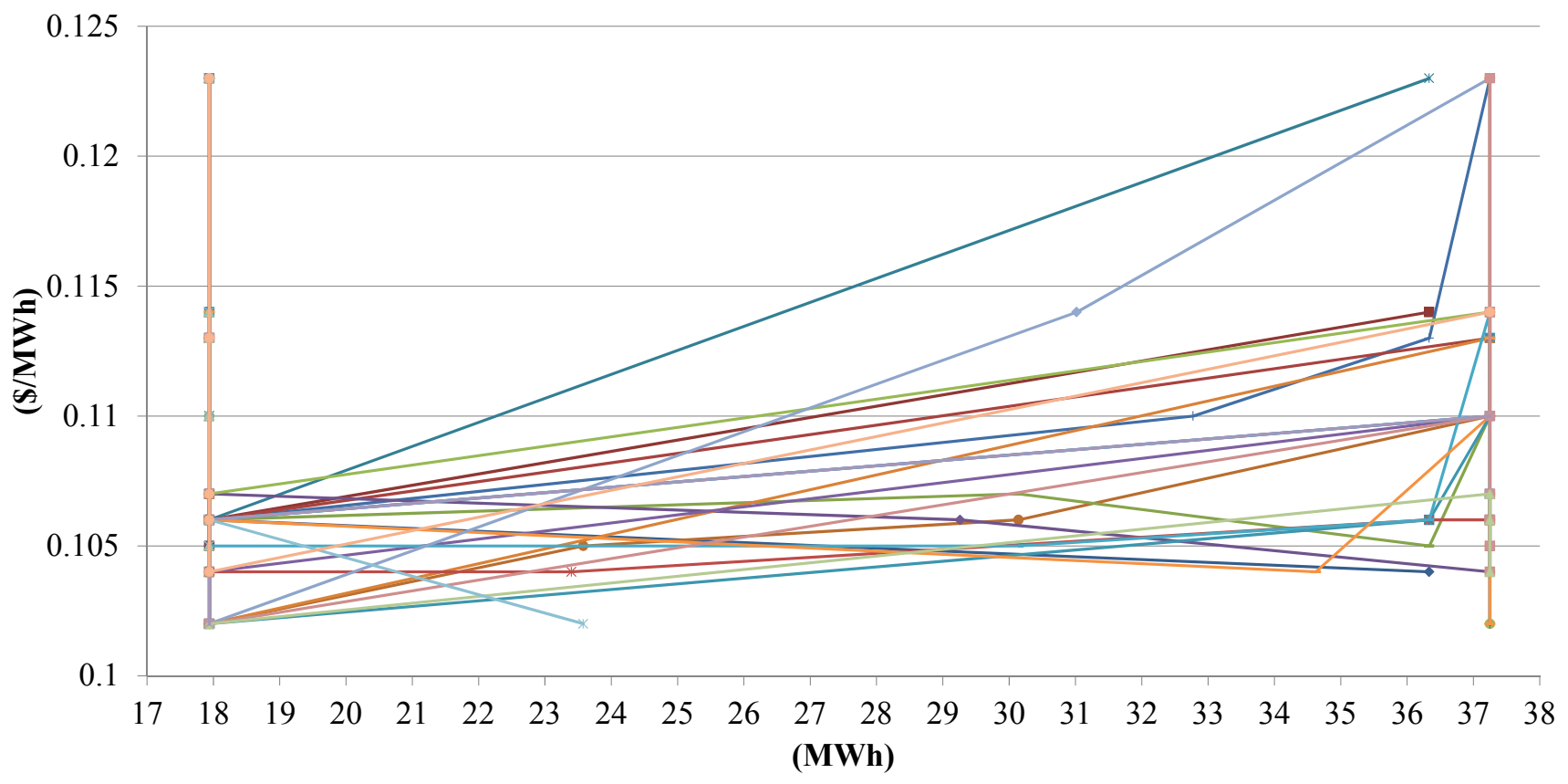

(a)

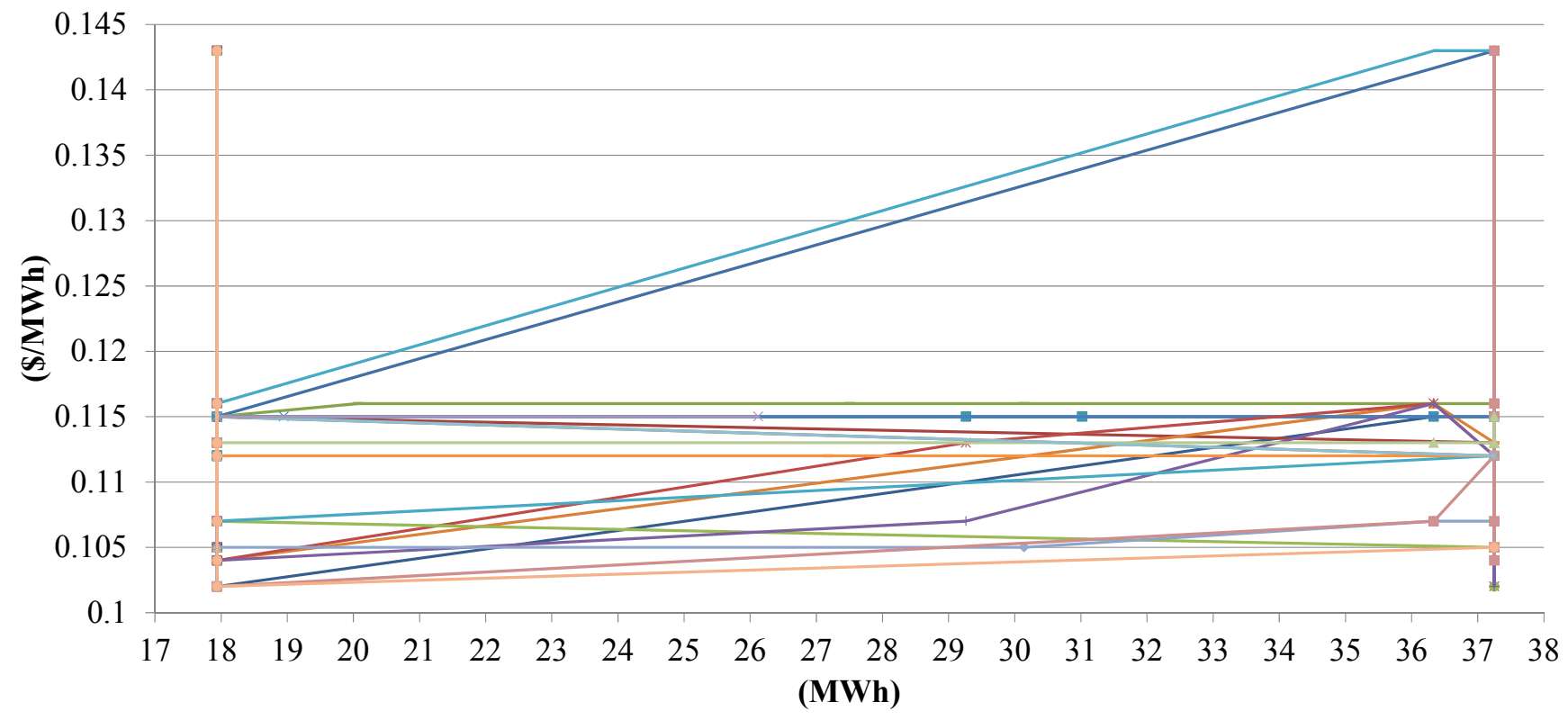

(b) 
Figure 9. Cont.

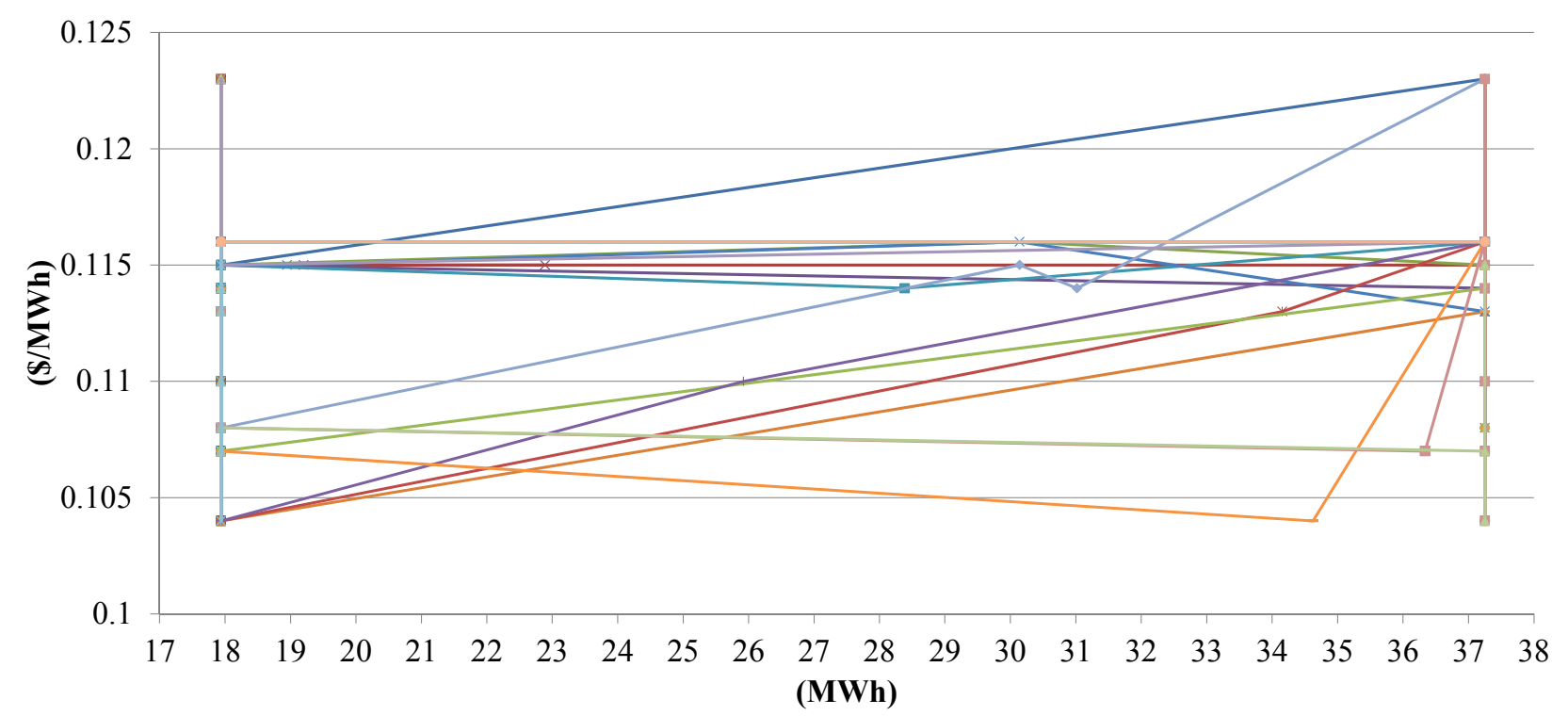

(c)

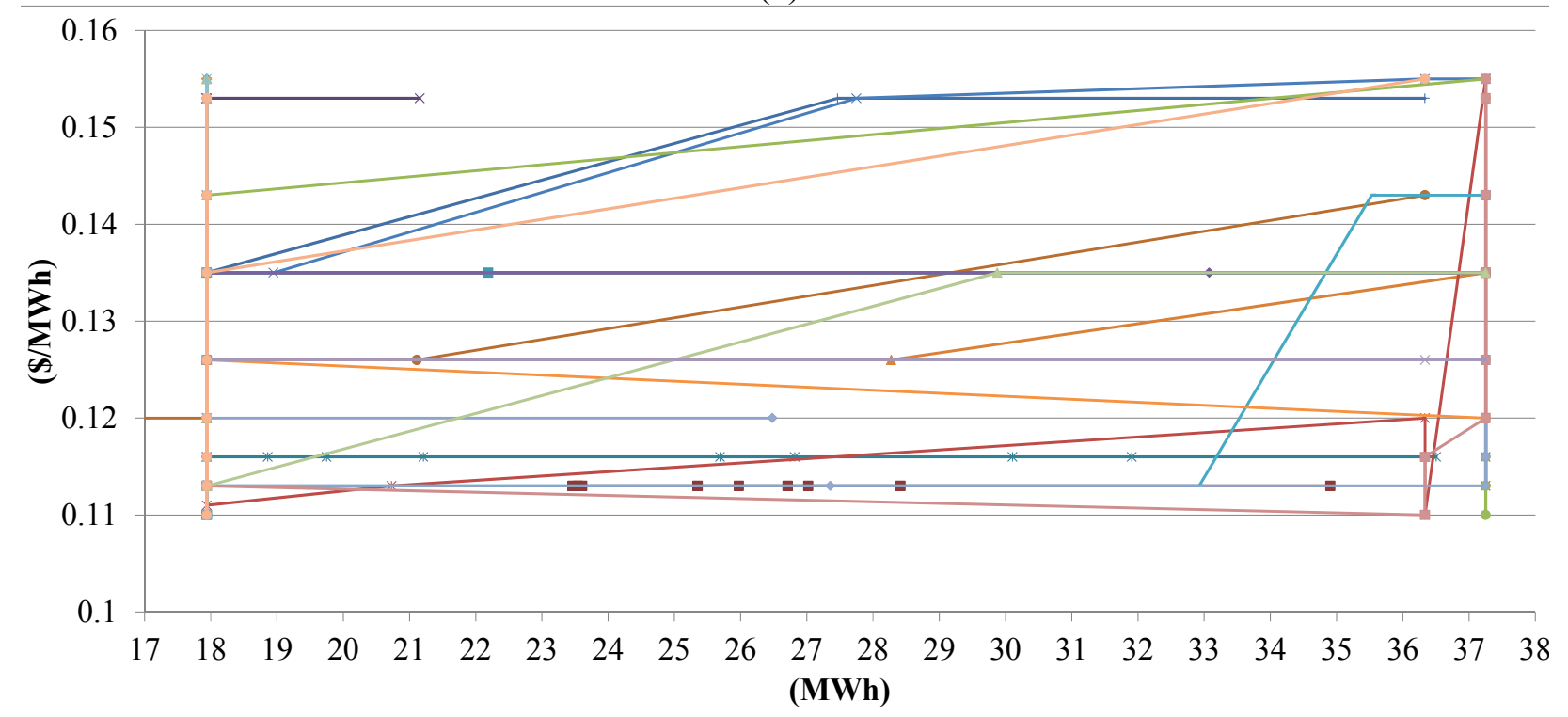

(d)

When the function is nonincreasing in some intervals two period moving average approach is used for determining the nondecreasing function as depicted on Figure 11. Also, it is assumed the bid curve is perfectly inelastic in last point as depicted on Figure 11 (red line). Thus, GENCO can create perfectly inelastic bid curve consisting of energy bided marginal cost of producing energy or ancillary (Figure 12).

As the profit tolerance rises from $\$ 0$ to $\$ 1380$ for the each hour (Table 3), the profit decreases from $\$ 98,193$ to $\$ 96,959$, daily $\alpha-V a R$ increases from $\$ 0$ to $\$ 44,037$ and daily $\alpha-C V a R$ increases from $\$ 0$ to $\$ 33120$. In other words, when GENCO decides the average hourly profit of $15 \%$ worst scenarios should be at least $\$ 1380$ then GENCO can expect daily profit of $\$ 33120$ in $15 \%$ worst scenarios, the minimal daily profit GENCO can expect with the confidence of $85 \%$ is $\$ 44,037$, and the average profit GENCO can expect is $\$ 96,959$. 
Figure 10. The marginal cost curves for spinning reserve for the profit tolerances (a) $\operatorname{minCVaR}(t)=0 ;$ (b) $\operatorname{minCVaR}(t)=400 ;$ (c) $\operatorname{minCVaR}(t)=800$; (d) $\operatorname{minCVaR}(t)=1380$.

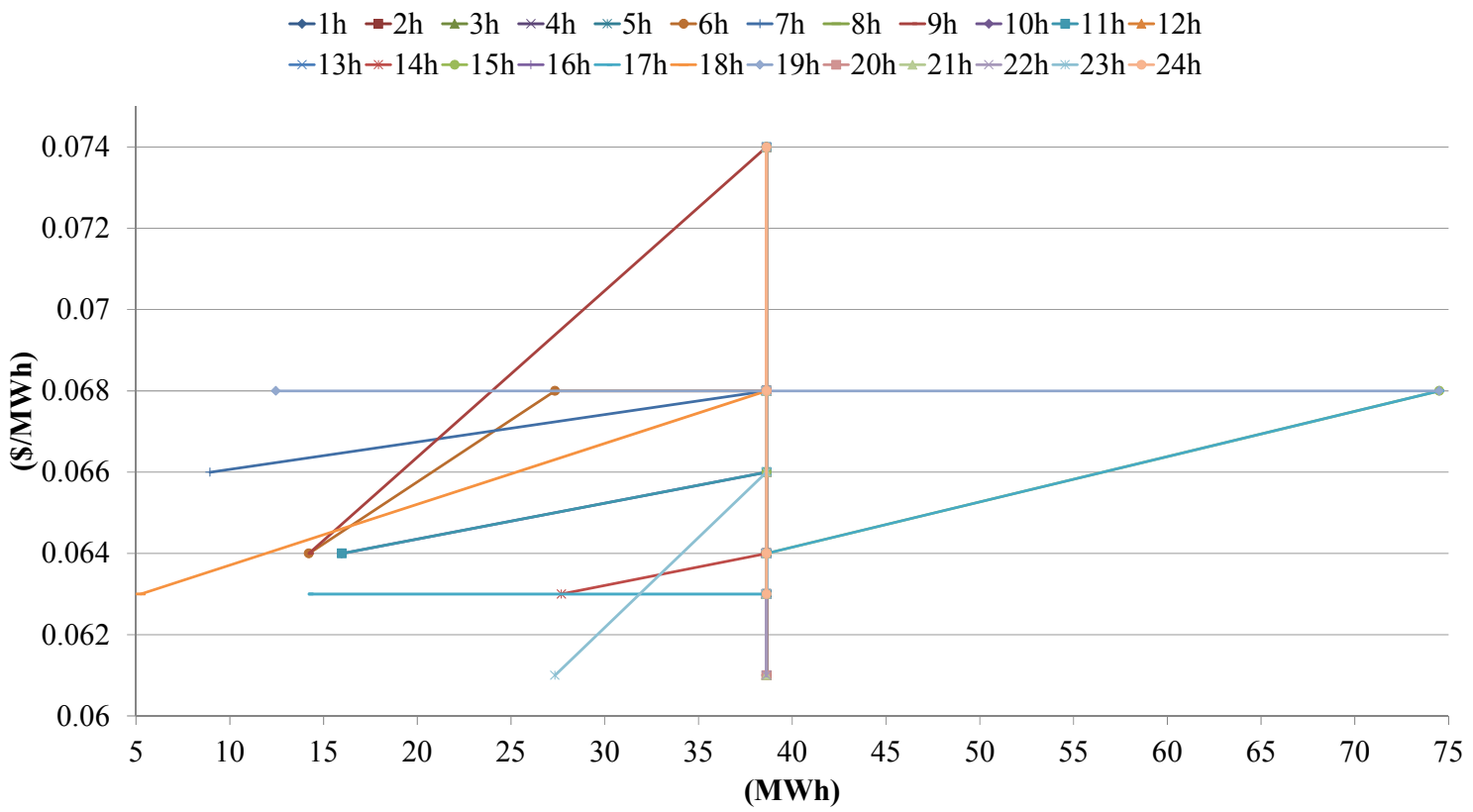

(a)

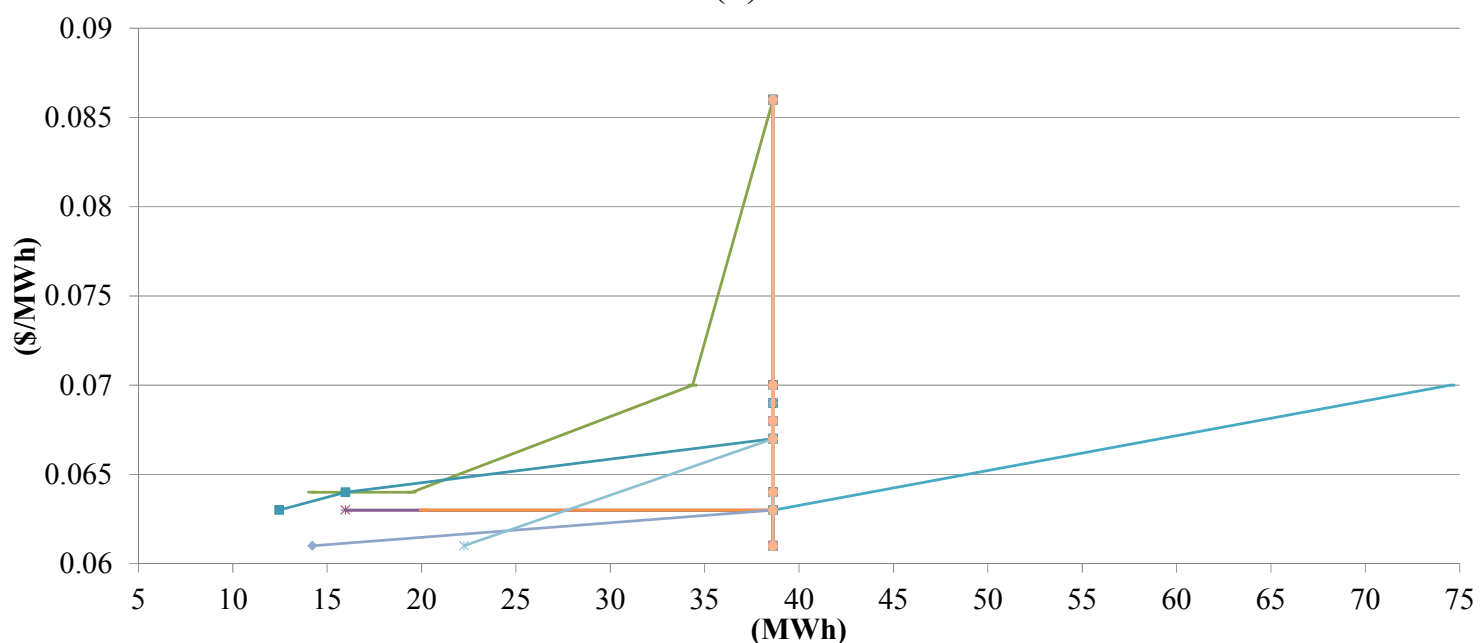

(b)

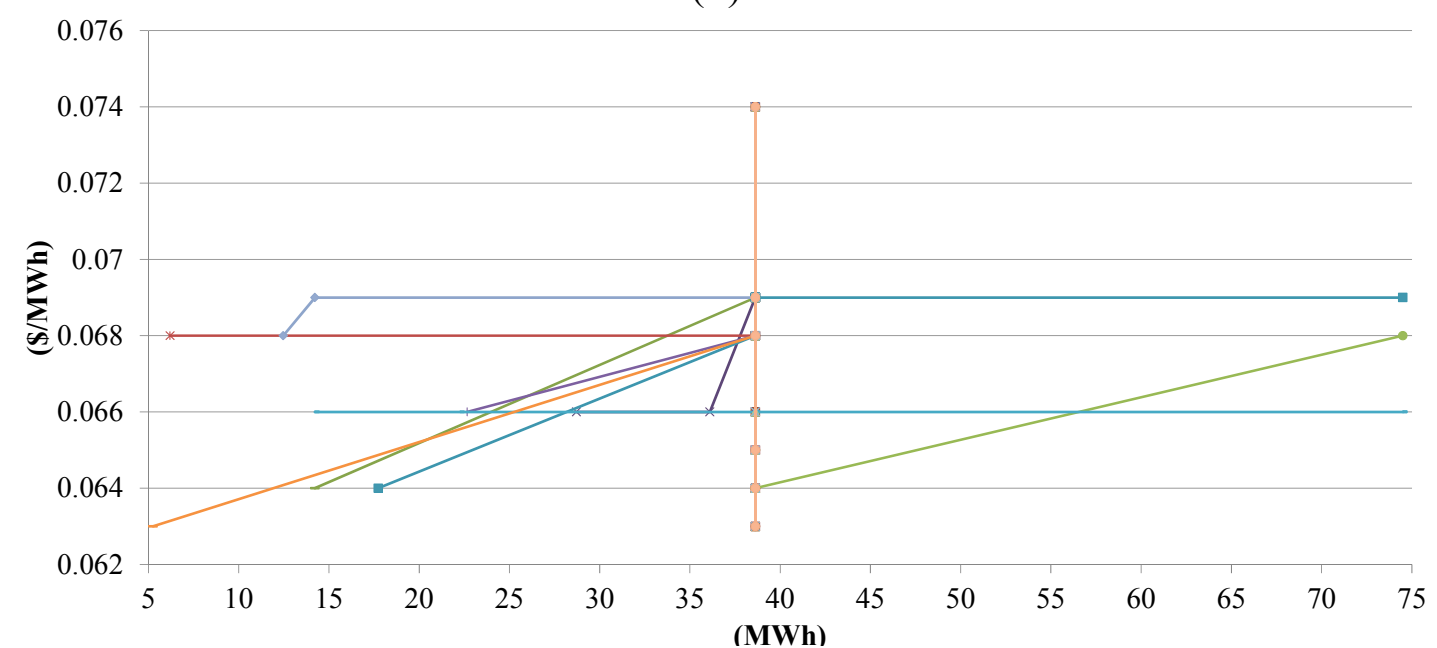

(c) 
Figure 10. Cont.

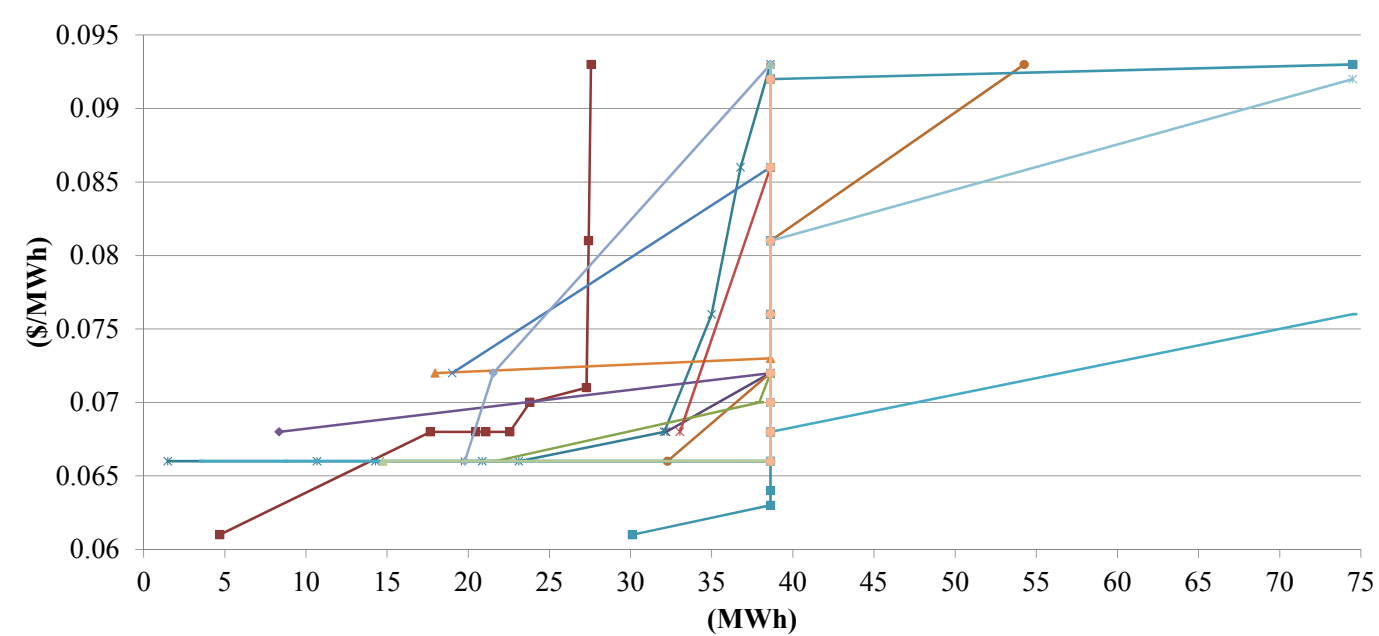

(d)

Figure 11. Creating nondecreasing bid curve from inapplicable shadow price curve.

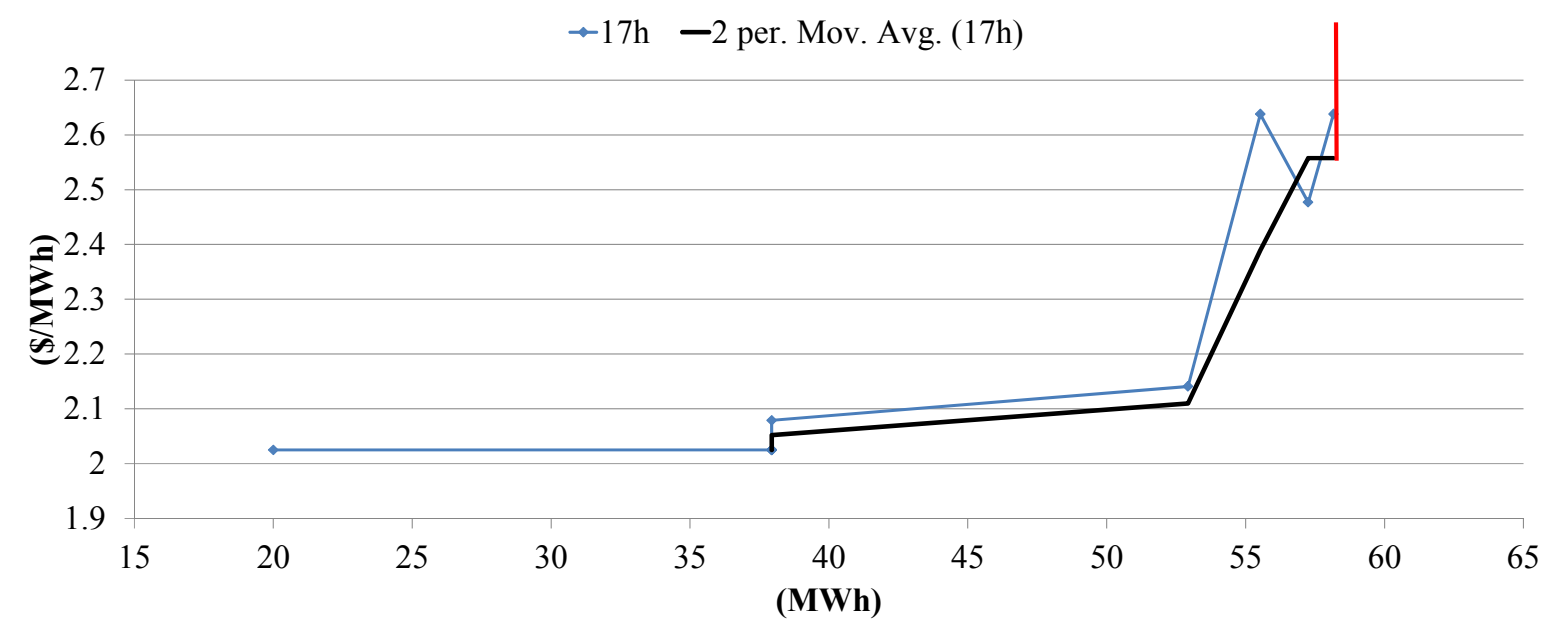

Figure 12. The perfectly inelastic energy bid curves for (a) $\operatorname{minCVaR}(t)=0$; (b) $\operatorname{minCVaR}(t)=1380$ based on results shown in Figure 8 .

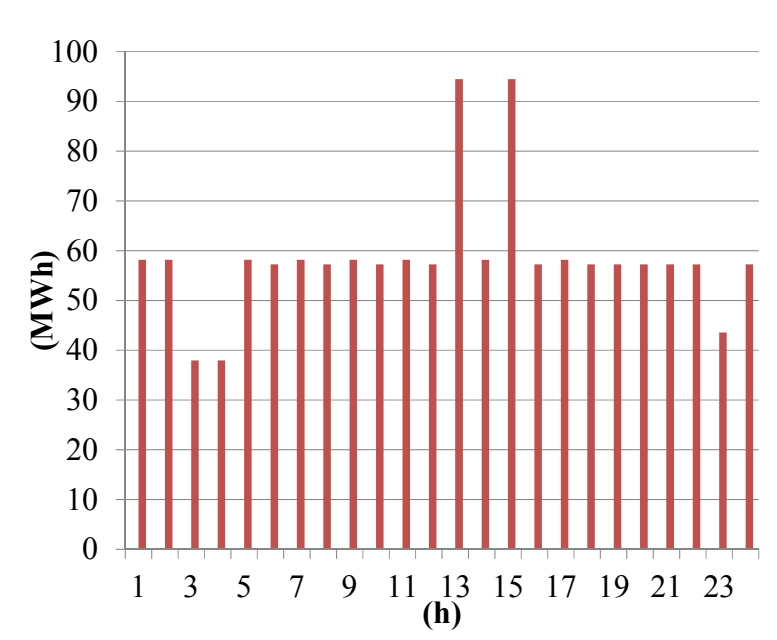

(a)

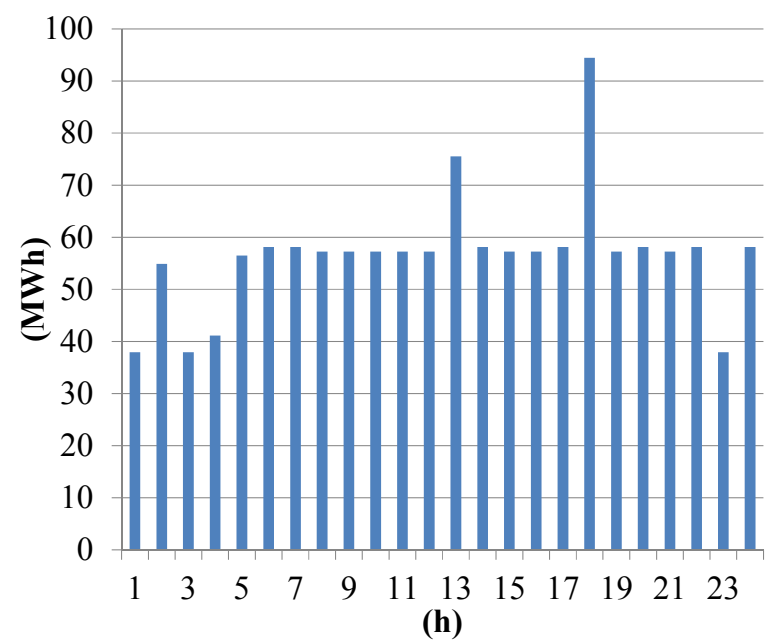

(b) 
The obtained results confirm a risk aversion principle, generally GENCO should avoid hours with high price deviation as can be seen for the 13-th and 15-th hour in Figure 12. In this case study GENCO should seek certainty even at cost of reducing its profit. The results obtained using normal PDF for representing DAM prices confirm risk aversion principle, but for higher exactness lognormal probability distribution should be used to the pronounce benefits of this approach.

\section{Conclusions}

The approach presented in this work assesses the problem which the price-taker hydro generating company faces when participating in the simultaneous day-ahead energy and ancillary services markets and which results in the risk-constrained approach for pricing energy and ancillary services.

The results of this case study justify the use of a simplified approach where water shadow price was considered constant over planning horizon. It was also shown that perfectly inelastic bid curves are appropriate for a price-taker hydro generating company. It was shown that reducing risk of financial losses costs, and that these cost can be easily measured.

Since the research was done on relatively small number of scenarios, further work should be done to implement computational efficient algorithms which will tackle dimensionality issue and improve computational time. For higher exactness lognormal probability distribution should be used which will pronounce benefits of this risk-constrained approach.

\section{Acknowledgments}

This work has been supported by the project "Sustainable Energy and Environment in the Western Balkans-SEEWB" inside the HERD (Higher Education, Research and Development) Energy Programme, funded by the Norwegian Ministry of Foreign Affairs and the European Community Seventh Framework Programme under grant No. 285939 (ACROSS).

\section{Author Contributions}

Perica Ilak and Slavko Krajcar have contributed in developing the ideas, formulation of the optimization problem and calibrating the model presented in this work. Ivan Rajšl and Marko Delimar have been involved in implementation of the problem and analysis of the results. All the authors are involved in preparing the manuscript. Perica Ilak and Slavko Krajcar are responsible for the integrity of the work as a whole.

\section{Nomenclature:}

Sets

$T \quad$ Set of indices of the steps of the optimization period, planning horizon, $T=\left\{1,2, \ldots, T_{\max }\right\}, t \in T, T_{\max } \in N$

$I \quad$ Set of indices of the reservoirs/plants, $I=\{$ “Križ", "Lokve", "Lepenica", "Bajer" $\}, i \in I$.

$J \quad$ Set of indices of the perf. curves $J=\{1$-high 1vl., 2-middle lvl., 3-low lvl.,,$j \in J$. 
$U_{i} \quad$ Set of upstream reservoirs of plant $i$.

$B \quad$ Set of indices of the blocks of the piecewise linearization of the unit performance curve $B=\{1,2,3\}, b \in B$.

$\Omega \quad$ Set of indices representing future states of knowledge, it is a set of scenarios that can occur, $\Omega=\left\{1,2, \ldots, \Omega_{\max }\right\}, \omega \in \Omega, \Omega_{\max } \in \mathbb{N}$.

$N \quad$ Set of indices of the profit tolerances $N=\left\{1,2, \ldots, N_{\max }\right\}, n \in N$.

Parameters

$M \quad$ Conversion factor equal to $3600\left(\mathrm{~m}^{3} \cdot \mathrm{s} \cdot \mathrm{m}^{-3} \cdot \mathrm{h}^{-1}\right)$.

$X_{\max }(i) \quad$ Maximal content of the reservoir $i\left(\mathrm{~m}^{3}\right)$.

$X_{l}(i) \quad l$-th discrete level of the content of the reservoir $i, l \in\{1,2,3,4\}\left(\mathrm{m}^{3}\right)$.

$X_{\min }(i) \quad$ Minimal content of the reservoir $i\left(\mathrm{~m}^{3}\right)$.

$X(i, 0) \quad$ Initial water content of the reservoir $i\left(\mathrm{~m}^{3}\right)$.

$X(i, 24) \quad$ Final water content of the reservoir $i\left(\mathrm{~m}^{3}\right)$.

$W(i, t, \omega) \quad$ Forecasted natural water inflow of the reservoir $i$ in time step $t$ and scenario $\omega\left(\mathrm{m}^{3} / \mathrm{s}\right)$.

$\Pi_{\text {spot }}(t, \omega)$ Forecasted price of real-time electricity market in time step $t$ and scenario $\omega(\$ / M W h)$.

$\Pi_{e}(t, \omega) \quad$ Forecasted price of day ahead electricity market in time step $t$ and scenario $\omega(\$ / M W h)$.

$\Pi_{r}(t, \omega) \quad$ Forecasted price of day ahead regulation market in time step $t$ and scenario $\omega(\$ / M W h)$.

$\Pi_{s}(t, \omega) \quad$ Forecasted price of day-ahead 10 minute spinning reserve market in time step $t$ and scenario $\omega(\$ / M W h)$.

$Q_{\min }(i) \quad$ Minimum water discharge of plant $i\left(\mathrm{~m}^{3} / \mathrm{s}\right)$.

$Q_{\max }(i) \quad$ Maximum water discharge of plant $i\left(\mathrm{~m}^{3} / \mathrm{s}\right)$.

$Q_{\max }(i, b) \quad$ Maximum water discharge of block $b$ of plant $i\left(\mathrm{~m}^{3} / \mathrm{s}\right)$.

$B_{\min }(i) \quad$ Ecological minimum of plant $i\left(\mathrm{~m}^{3} / \mathrm{s}\right)$.

$p_{i} \quad$ Ancillary services probability matrix of size $\Omega_{\max } \times T_{\max }$

$\forall i \in\{$ rup, rdown, del $\}$.

$p(\omega) \quad$ Probability of price scenario $\omega$.

$P 0_{n}(i) \quad$ Minimum power output of plant $i$ for performance curve $n$, $n \in\{1,2,3,4,5\}$ (MW).

$P_{\max }(i) \quad$ Capacity of plant $i(\mathrm{MW})$.

$\rho_{j}(i, b) \quad$ Slope of the block $b$ of the performance curve $j$ of plant $i\left(\mathrm{MWs} / \mathrm{m}^{3}\right)$.

$\rho^{-1}(i, t, \omega)$ Conversion factor used for converting $\left(\mathrm{m}^{3}\right)$ to $(\mathrm{MWh})$ for reservoir $i$ in particular time step $t$. Meaning calculation of reservoir energy potential $\left(\mathrm{MWh} / \mathrm{m}^{3}\right)$ in time step $t$.

$p_{\text {rup }}(t, \omega) \quad$ Probability of being in Regulation-up state in time step $t$ and scenario $\omega$.

$p_{\text {rdown }}(t, \omega$, Probability of being in Regulation-down state in time step $t$ and scenario $\omega$.

$p_{\text {del }}(t, \omega) \quad$ Probability of spinning reserve to be activated in time step $t$ and scenario $\omega$.

$\operatorname{MSR}(i) \quad$ Maximum sustain ramp rate of plant $i(\mathrm{MW} / \mathrm{min})$. 
$U P(i) \quad$ Ramping up limit of plant $i(\mathrm{MW} / \mathrm{h})$.

$D R(i) \quad$ Ramping down limit of plant $i(\mathrm{MW} / \mathrm{h})$.

$\Delta_{l}(i) \quad$ Difference between maximal values of two neighboring perf. curves of plant $i$, $l \in\{1,2,3,4\}$ (MW).

$\delta_{l}(i) \quad$ Difference between minimal values of two neighboring perf. curves of plant $i, l \in\{1,2,3,4\}(\mathrm{MW})$.

$\min C \operatorname{VaR}(n n$-th profit tolerance in time step $t$.

$\alpha \quad$ Confidence level of a profit probability density function.

$\beta \quad$ Confidence level of a loss probability density function.

Marginal Values

$\lambda(i, \omega) \quad$ Shadow price of constraint determining final $i$-th reservoir capacity and is paired with right-hand side (r.h.s.) unit increment $\Delta \zeta(i, \omega)$ to the zero of Equation (43a) for scenario $\omega\left(\$ / \mathrm{m}^{3}\right)$.

$\Psi(i, t, \omega) \quad$ Shadow price of water balance equation of $i$-th reservoir, and is paired with r.h.s. unit increment $\Delta W(i, t, \omega)$ of Equation (1) for scenario $\omega$ and time step $t\left(\$ / \mathrm{m}^{3}\right)$.

$\kappa^{X} \max (i, t, \omega$ Shadow price of constraint determining maximum $i$-th reservoir capacity, and is paired with r.h.s. unit increment $\Delta X_{\max }(i, t, \omega)$ of constraint (2) for scenario $\omega$ and time step $t\left(\$ / \mathrm{m}^{3}\right)$.

$v^{X_{\min }}(i, t, \omega$ Shadow price of constraint determining minimum $i$-th reservoir capacity, and is paired with r.h.s. unit decrement $-\Delta X_{\min }(i, t, \omega)$ of constraint (2) for scenario $\omega$ and time step $t\left(\$ / \mathrm{m}^{3}\right)$.

$\kappa^{P_{\max }}(i, t, \omega$ Shadow price of constraint determining maximum $i$-th generator capacity, and is paired with r.h.s. unit increment $\Delta P_{\max }(i, t, \omega)$ of constraint (7)-(12) for scenario $\omega$ and time step $t$ (\$/MW).

$v^{P_{0}}(i, t, \omega) \quad$ Shadow price of constraint determining minimum $i$-th generator capacity, and is paired with r.h.s. unit decrement $-\Delta P_{0}(i, t, \omega)$ of constraint (7)-(12) for scenario $\omega$ and time step $t(\$ / \mathrm{MW})$.

\section{Variables}

$x(i, t, \omega) \quad$ Water content of the reservoir $i$ at the end of time step $t$ and scenario $\omega\left(\mathrm{m}^{3}\right)$.

$X_{\text {avg }}(i, t, \omega)$ Average water content of the reservoir $i$ in time step $t$ and scenario $\omega\left(\mathrm{m}^{3}\right)$.

$q(i, t, \omega) \quad$ Water discharge of plant $i$ in time step $t$ and scenario $\omega\left(\mathrm{m}^{3} / \mathrm{s}\right)$.

$q_{u}(i, t, b, \omega)$ Water discharge of block $b$ of plant $i$ in time step $t$ and scenario $\omega\left(\mathrm{m}^{3} / \mathrm{s}\right)$.

$s(i, t, \omega) \quad$ Spillage of the reservoir $i$ in time step $t$ and scenario $\omega\left(\mathrm{m}^{3} / \mathrm{s}\right)$.

$d_{k}(i, t, \omega) \quad 0 / 1$ variable used for discretization of performance curves and scenario $\omega$, $k \in\{1,2,3,4\}$.

$w(i, t, 0, \omega) \quad 0 / 1$ variable which is equal to 1 if plant $i$ is on-line in time step $t$ and scenario $\omega$.

$w(i, t, b, \omega) \quad 0 / 1$ variable which is equal to 1 if water discharged by plant $i$ has exceeded block $b$ in time step $t$ and scenario $\omega$.

$P(i, t, \omega) \quad$ Power output of plant $i$ in time step $t$ and scenario $\omega$ (MW). 
$P_{e}(i, t, \omega) \quad$ Power output of plant $I$ committed to energy market in time period $t$ and scenario $\omega$ (MW).

$P_{r}(i, t, \omega) \quad$ Regulation service capacity of plant $i$ in time period $t$ and scenario $\omega(\mathrm{MW})$.

$P_{S}(i, t, \omega) \quad 10$ min spinning reserve of plant $i$ available for increase of output power in time period $t$ and scenario $\omega(\mathrm{MW})$.

$E_{e}(i, t, \omega) \quad$ Electricity produced for energy market by plant $i$ in time period $t$ and scenario $\omega$ (MWh).

$E_{r}(i, t, \omega) \quad$ Electricity produced for regulation service by plant $i$ in time period $t$ and scenario $\omega$ (MWh).

$E_{S}(i, t, \omega) \quad$ Electricity produced for spinning reserve service by plant $i$ in time period $t$ and scenario $\omega$ (MWh).

$\zeta(t) \quad$ Real variable in special function $F_{\alpha}$ used for obtaining $\alpha-\operatorname{VaR}(t)$ and $\alpha-\operatorname{CVaR}(t), \zeta \in \mathbb{R}$.

\section{Conflicts of Interest}

The authors declare no conflict of interest.

\section{References}

1. Zhang, D.; Luh, P.B.; Zhang, Y. A bundle method for hydrothermal scheduling. IEEE Trans. Power Syst. 1999, 14, 1355-1361.

2. George, A.; Reddy, C.; Sivaramakrishnan, A.Y. Multi-objective, short-term hydro thermal scheduling based on two novel search techniques. Int. J. Eng. Sci. Technol. 2010, 2, 7021-7034.

3. Dhillon, J.S.; Kothari, D.P. Multi-Objective Short-Term Hydrothermal Scheduling Based on Heuristic Search Technique. Asian J. Inf. Technol. 2007, 6, 447-454.

4. Zhang, J.L.; Ponnambalam, K. Hydro energy management optimization in a deregulated electricity market. Optim. Eng. 2006, 7, 47-61.

5. Horsley, A.; Wrobel, A.G. Profit-maximizing operation and valuation of hydroelectric plant: A new solution to the Koopmans problem. J. Econ. Dyn. Control 2007, 31, 938-970.

6. Perekhodtsev, D.; Lave, L.B. Efficient Bidding for Hydro Power Plants in Markets for Energy and Ancillary Services; 06-003WP; Massachusetts Institute of Technology (MIT) Center for Energy and Environmental Policy Research: Cambridge, MA, USA, 2005.

7. Koopmans, T.C. Water storage policy in a simplified hydroelectric system. In Proceedings of the First International Conference on Operational Reasearch, Oxford, UK, 2-5 September 1957.

8. Warford, J.; Munasinghe, M. Electricity Pricing: Theory and Case Studies; The John Hopkins University Press: London, UK, 1982.

9. Horsley, A.; Wrobel, A.J. Efficiency Rents of Storage Plants in Peak-Load Pricing, I: Pumped Storage; London School of Economics and Political Science: London, UK, 1996.

10. Horsley, A.; Wrobel, A.J. Efficiency Rents of Storage Plants in Peak-Load Pricing, II: Hydroelectricity; London School of Economics and Political Science: London, UK, 1999; pp. 17-20.

11. Sorokin, A.; Rebennack, S.; Pardalos, P.; Iliadis, N.A.; Pereira, D. Handbook of Networks in Power Systems; Springer Berlin Heidelberg: Berlin, Germany, 2012; pp. 41-59. 
12. Baillo, A.; Ventosa, M.; Rivier, M.; Ramos, A. Strategic bidding under uncertainty in a competitive electricity market. In Proceedings of the International Conference on Probabilistic Methods Applied to Power Systems, Madeira, Portugal, 25-28 September 2000.

13. Conejo, A.J.; Nogales, F.J.; Arroyo, M.A. Price-Taker Bidding Strategy under Price Uncertainty. IEEE Trans. Power Syst. 2002, 17, 1081-1088.

14. Zhang, H.; Gao, F.; Wu, J.; Liu, K.; Liu, X. Optimal Bidding Strategies for Wind Power Producers in the Day-Ahead Electricity Market. Energies 2012, 5, 4804-4823

15. Margaris, I.D.; Hansen, A.D.; Sørensen, P.; Hatziargyriou, N.D. Illustration of Modern Wind Turbine Ancillary Services. Energies 2010, 3, 1290-1302.

16. Lehmann, P.; Creutzig, F.; Ehlers, M.-H.; Friedrichsen, N.; Heuson, C.; Hirth, L.; Pietzcker, R. Carbon Lock-Out: Advancing Renewable Energy Policy in Europe. Energies 2012, 5, 323-354.

17. Kabouris, J.; Kanellos, F.D. Impacts of Large Scale Wind Penetration on Energy Supply Industry. Energies 2009, 2, 1031-1041.

18. Garcia-Gonzalez, J.; Parrilla, E.; Mateo, A. Risk-averse profit-based optimal scheduling of a hydro-chain in the day-ahead electricity market. Eur. J. Oper. Res. 2007, 181, 1354-1369.

19. Garcia-Gonzalez, J.; Parrilla, E.; Mateo, A.; Moraga, R. Building optimal generation bids of a hydro chain in the day-ahead electricity market under price uncertainty. In Proceedings of the International Conference on Probabilistic Methods Applied to Power Systems, Stockholm, Sweeden, 11-15 June 2006.

20. Rockafellar, R.T.; Uryasev, S. Conditional Value-at-Risk for General Loss Distributions; University of Washington, Department of Mathematics: Seattle, WA, USA, 2001.

21. Artzner, P.; Delbaen, F.; Eber, J.M.; Heath, D. Thinking coherently. Risk 1997, 10, 68-91.

22. Acerbi, C. Spectral measures of risk: A coherent representation of subjective risk aversion. J. Bank. Financ. 2002, 26, 1505-1518.

23. Rockafellar, R.T. Coherent Approaches to Risk in Optimization under Uncertanty. Tutor. Oper. Res. Inf. 2007, 2007, 38-61.

24. Mariano, S.J.P.; Catalao, J.P.S.; Mendes, V.M.F.; Ferreira, L.A.F.M. Profit-based short-term hydro scheduling considering head-dependent power generation. In Proceedings of the IEEE Power Tech 2007, Lausanne, Switzerland, 1-5 July 2007.

25. Ponrajah, R.A.; Witherspoon, J.; Galiana, F.D. Systems to optimize conversion efficiencies at Ontario Hydro's hydroelectric plants. In Proceedings of the IEEE Transactions on Power Systems, Columbus, OH, USA, 16-19 November 1998.

26. Rajšl, I.; Ilak, P.; Delimar, M.; Krajcar, S. Dispatch Method for Independently Owned Hydropower Plants in the Same River Flow. Energies 2012, 5, 3674-3690.

27. Guo, S.; Chen, J.; Li, Y.; Liu, P.; Li, T. Joint Operation of the Multi-Reservoir System of the Three Gorges and the Qingjiang Cascade Reservoirs. Energies 2011, 4, 1036-1050.

28. Xu, B.; Zhong, P.-A.; Wan, X.; Zhang, W.; Chen, X. Dynamic Feasible Region Genetic Algorithm for Optimal Operation of a Multi-Reservoir System. Energies 2012, 5, 2894-2910.

29. Zheng, Y.; Fu, X.; Wei, J. Evaluation of Power Generation Efficiency of Cascade Hydropower Plants: A Case Study. Energies 2013, 6, 1165-1177. 
30. Guan, X.; Svoboda, A.; Li, C.A. Scheduling hydro power systems with restricted operating zones and discharge ramping constraints. IEEE Trans. Power Syst. 1999, 14, 126-131.

31. Conejo, A.; Arroyo, J.; Contreras, J.; Villamor, F. Self-scheduling of a hydro producer in a pool-based electricity market. IEEE Trans. Power Syst. 2002, 17, 1265-1272.

32. Nilsson, O.; Sjelvgren, D. Variable splitting applied to modeling of start-up costs in short term hydro generation scheduling. IEEE Trans. Power Syst. 1997, 12, 770-775.

33. Nilsson, O.; Söder, L.; Sjelvgren, D. Integer modeling of spinning reserve requirements in short term scheduling of hydro systems. IEEE Trans. Power Syst. 1998, 13, 959-964.

34. The New York Independent System Operator (2012). Available online: http://www.nyiso.com (accessed on 13 July 2013).

35. Kuzle, I.; Bosnjak, D.; Tesnjak, S. An Overview of Ancillary Services in an Open Market Enviroment. WSEAS Trans. Power Syst. 2008, 7, 537-546.

36. Kazempour, S.J.; Hosseinpur, M.; Moghaddam, M.P. Self-Scheduling of a Joint Hydro and Pumped-Storage Plants in Energy, Spinning Reserve and Regulation Markets. In Proceedings of the Power \& Energy Society General Meeting, Calgary, Canada, 26-30 July 2009.

37. Yamin, H.Y. Review on methods of generation scheduling in electric power systems. Sci. Direct 2003, 69, 153-237.

38. Ilak, P.; Krajcar, S.; Rajšl, I.; Delimar, M. Profit Maximization of a Hydro Producer in a Day-Ahead Energy Market and Ancillary Service Markets. In Proceedings of the IEEE Region 8 Conference EuroCon, Zagreb, Croatia, 2-5 July 2013.

39. Hirst, E.; Kirby, B. Creating Competitive Markets for Ancillary Services; U.S. Department of Energy: Oak Ridge, TN, USA, 1997.

40. Rosenthal, R.E. GAMS/A User's Guide; GAMS Development Corporation: Washington, DC, USA, 2013.

41. Kuzle, I.; Pandžić, H.; Brezovec, M. Hydro Generating Units Maintenance Scheduling Using Benders Decomposition. Tech. Gaz. 2010, 17, 1-132.

42. Pandžić, H.; Conejo, A.; Kuzle. I. An EPEC Approach to the Yearly Maintenance Scheduling of Generating Units. IEEE Trans. Power Syst. 2013, 28, 922-930.

(C) 2014 by the authors; licensee MDPI, Basel, Switzerland. This article is an open access article distributed under the terms and conditions of the Creative Commons Attribution license (http://creativecommons.org/licenses/by/3.0/). 